\title{
A STUDY OF THE INTERPLAY BETWEEN THE LAW AND ORGANISATIONAL CODES OF CONDUCT WITH REGARDS TO SEXUAL HARASSMENT IN NEW ZEALAND
}

\author{
BY \\ HEIKE MENNE-SPOHR
}

A thesis

submitted to the Victoria University of Wellington

In partial fulfilment of the requirements for the degree of Master of Commerce

Victoria University of Wellington

2018 


\section{Abstract}

The aim of this research is to fill a gap in the New Zealand literature which is to investigate whether the sexual harassment legislation is being understood, implemented and monitored in organisations effectively.

This thesis explores how organisations in New Zealand are using tick-box compliance when implementing sexual harassment legislation into their employee policies and procedures documents due to the ambiguity of certain words. It looks at the role that Human Resources consultants and trade unions play, and further using the endogeneity model, the thesis explores the effect that tick-box compliance has on the legal consciousness of sexual harassment in organisations and third parties

Data was collected through semi-structured interviews with Human Resources professional at public and private sector organisations, Human Resources consultants as well as trade union representatives who are actively involved with the implementation and management of sexual harassment policies in the workplace.

It was found that organisations had implemented sexual harassment policies and procedures several years previously and that these had not been changed significantly due to a lack of change in the law itself. The findings also indicate that the organisations implement sexual harassment polices using a tick-box approach and they do not necessarily fully understand the legislation. It was suggested that the emphasis had shifted from sexual harassment to bullying and that the third parties like trade unions and Human Resources consultants see more cases of this than sexual harassment.

The thesis concludes that although organisations have sexual harassment policies and procedures, these are outdated and are not part of the legal consciousness of organisations, trade unions and Human Resources consultants. The ambiguous nature of the wording in the law itself and the lack of guidelines for organisations on how to implement them has resulted in tick-box compliance and organisations do not know if their policies are effective or not. Further the low penalties for sexual harassment behaviour means that there is no incentive for sexual harassment victims to raise complaints. 


\section{Acknowledgements}

Firstly, I would like to thank my family. Conrad thank you for your patience and listening to my rantings when nothing made sense in my head anymore, for giving me the space to study and for looking after the children.

To my children, even though you are both still very small, you have been the driving force behind me these last months and I dedicate this thesis to you both.

To my family $12000 \mathrm{kms}$ away, thank you for making me who I am today and your love and support over the years.

To my supervisor, Dr Amanda Reilley, if it had not been for your inspirational and passionate Labour and Employment Law class I would never have chosen this topic. Your depth of knowledge and guidance has helped me no end. Thank you for your patience with me when things were difficult with challenges and delays, and understanding and motivating me to continue and overcome the final hurdles.

To Dr Geoff Plimmer, thank you for giving me this opportunity from far off Germany in 2015. You were the first step in a long and eventful master's journey.

To my friend Maggie, you are an incredible person and thank you for your support and encouragement to keep going when I felt like I could not continue anymore. I am so lucky to have you as a friend.

Finally thank you to all the participants who agreed to being interviewed, your information and experience was greatly appreciated. Without your valuable contribution, I would not have been able to complete my thesis. 


\section{Table of Contents}

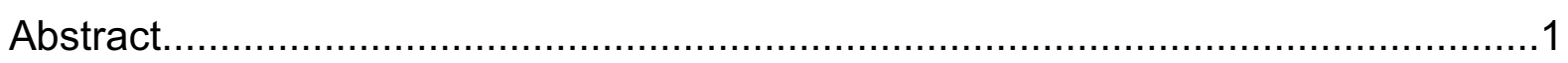

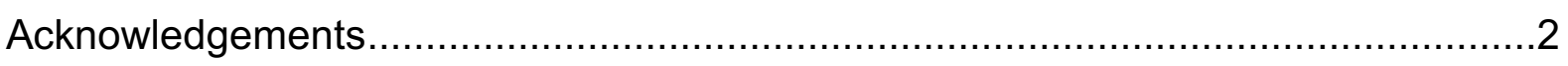

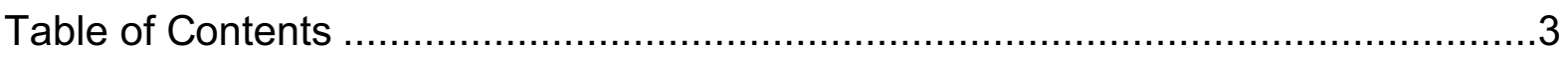

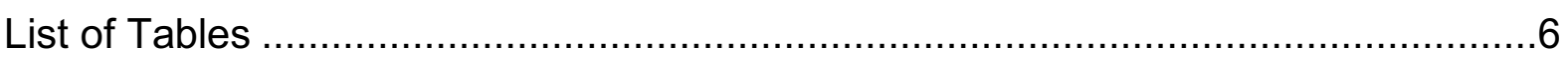

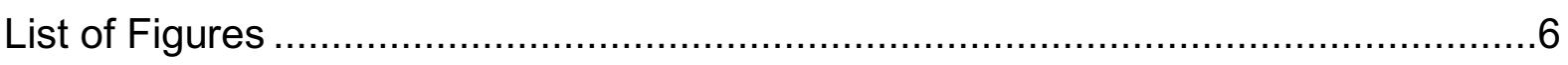

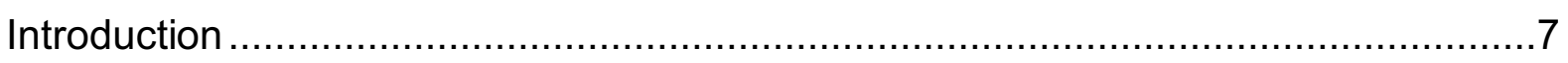

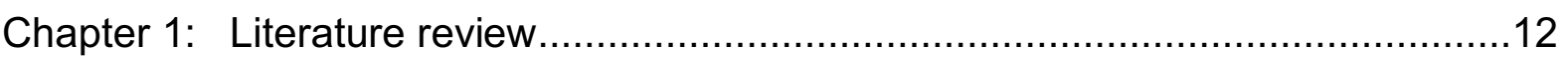

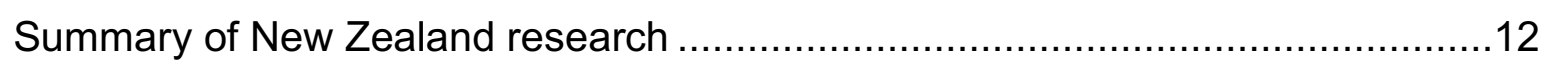

The theories of sexual harassment in organisations................................... 13

Workplace culture......................................................................... 13

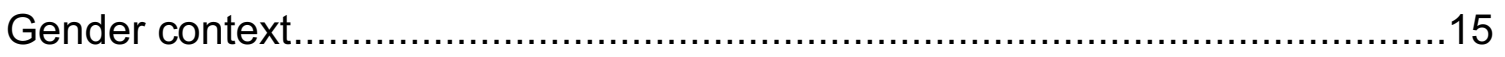

The implementation of the sexual harassment law in organisations ....................17

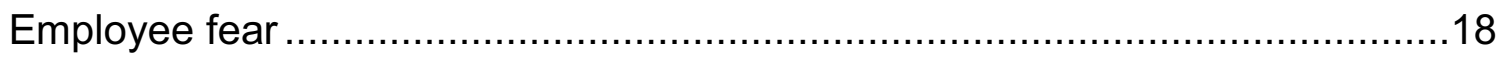

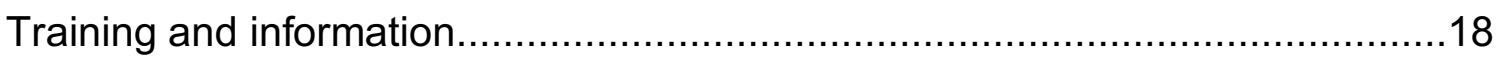

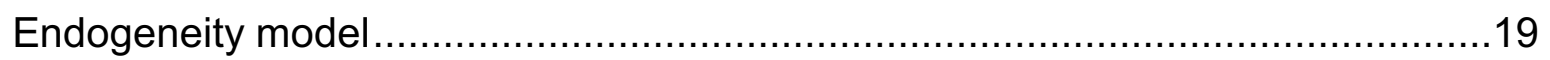

The strategic role of third parties in endogeneity ....................................21

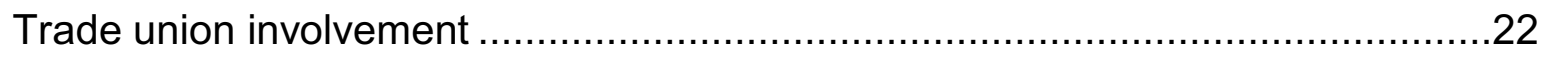

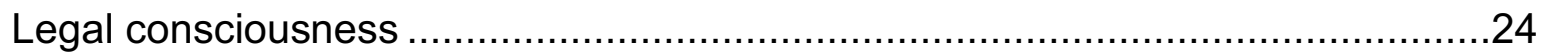

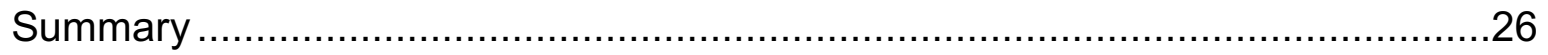

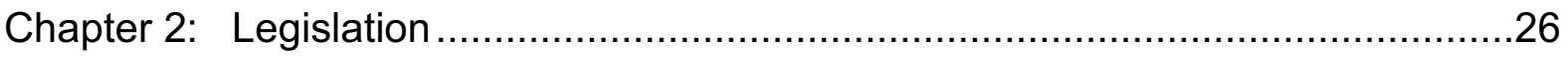

New Zealand sexual harassment legislation..........................................26

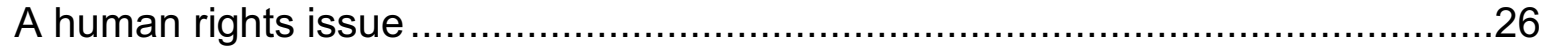

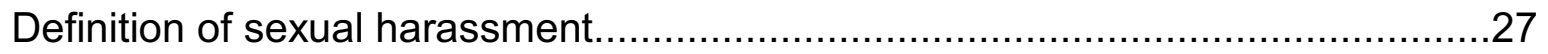

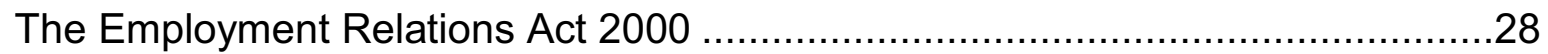

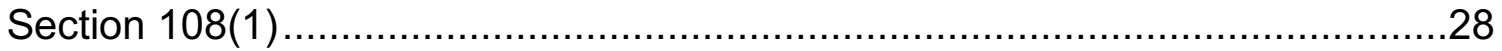

Section 117 Sexual or racial harassment by person other than employer..........29

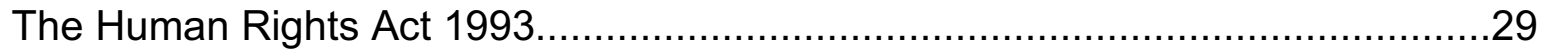

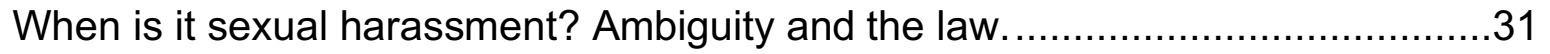

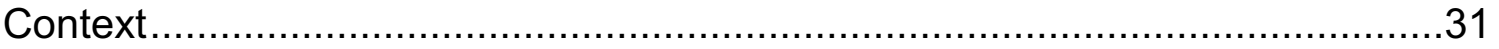

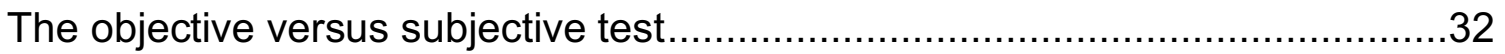

Harmful effect on employee employment .................................................. 
Coercion and annoyance

Cases

Newman v Taxi Lease Ltd t/a The Plant Place 24 November [2014] NZERA

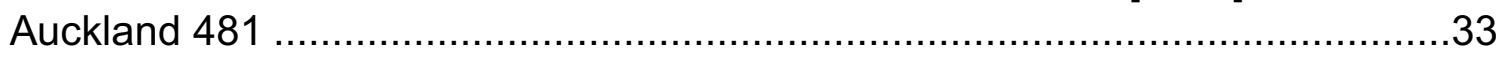

D v E Ltd 05 August [2013] NZERA Auckland 338.........................................

Kumar v Icehouse (NZ) Ltd [2006] ERNZ 381 (EmpC); L v M Ltd [1994] 1 ERNZ

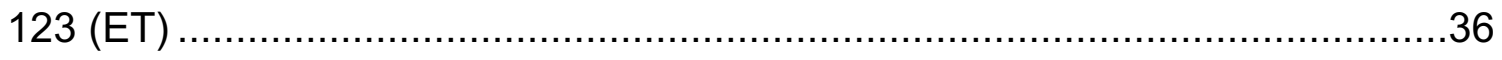

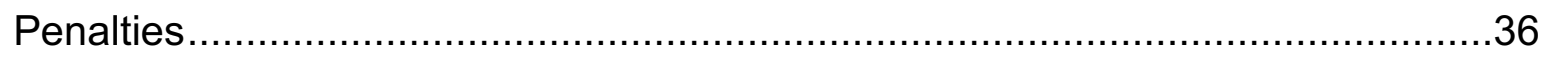

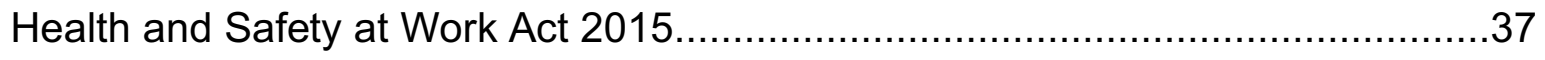

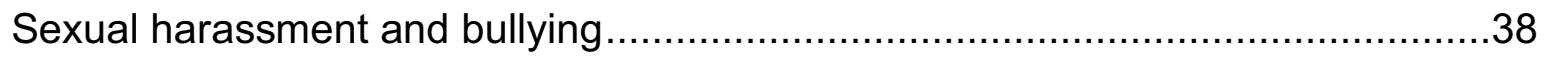

The prevalence of sexual harassment in the workplace .....................................38

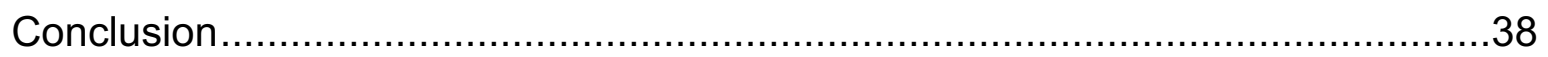

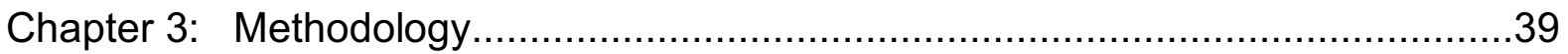

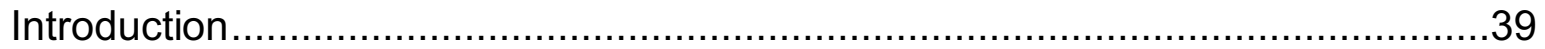

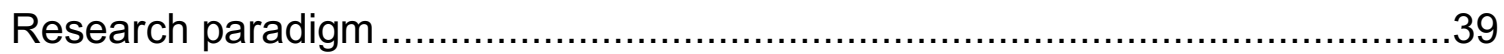

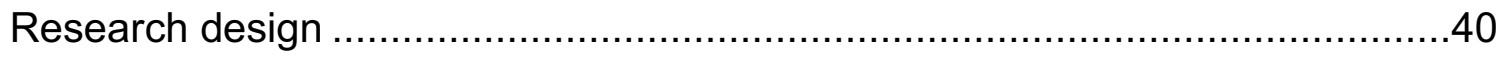

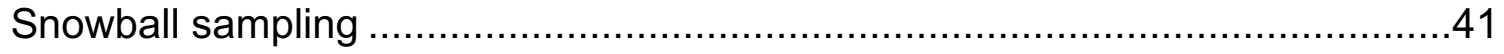

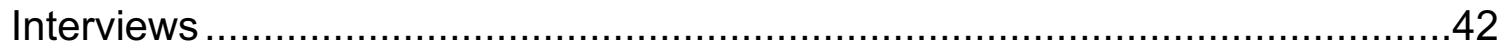

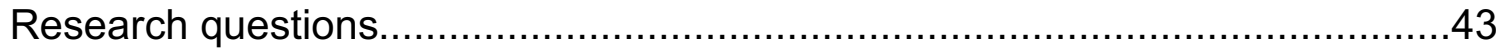

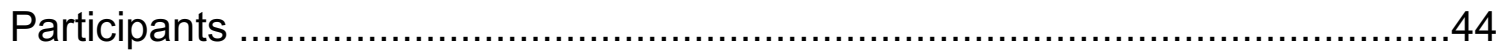

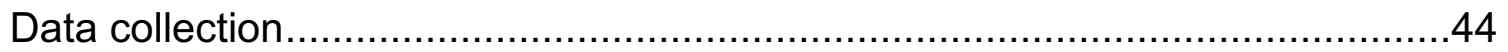

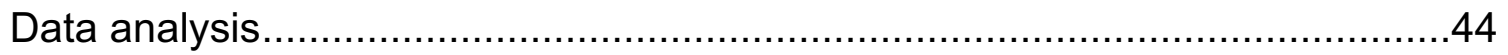

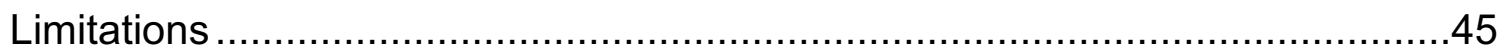

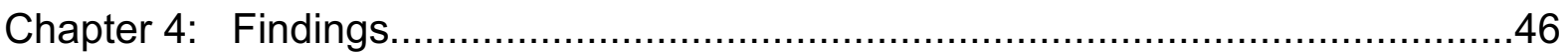

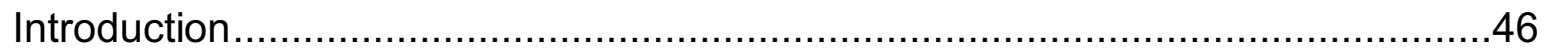

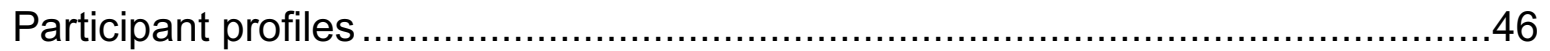

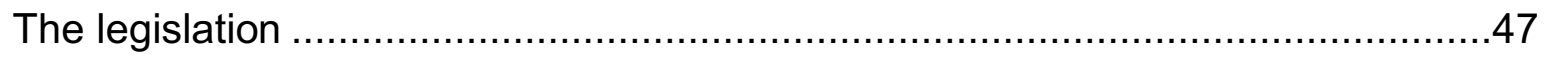

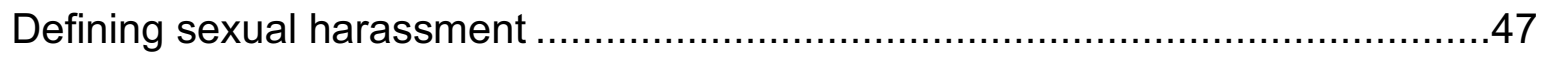

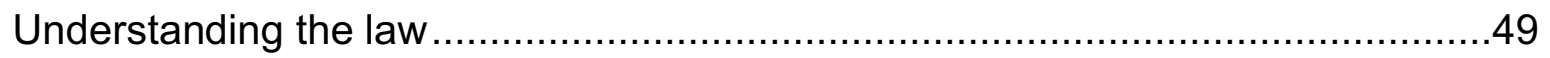

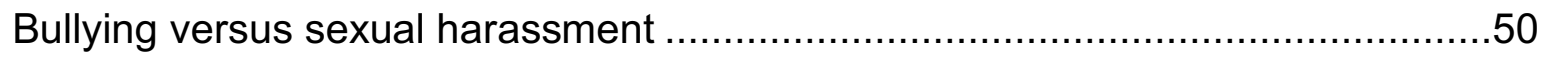

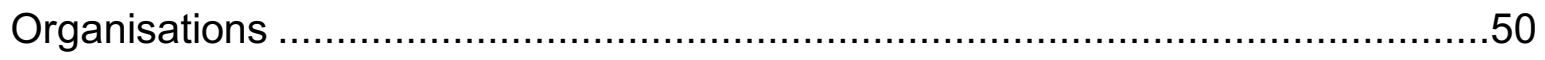

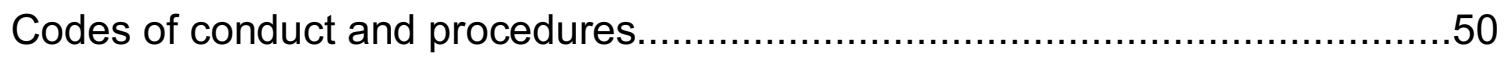

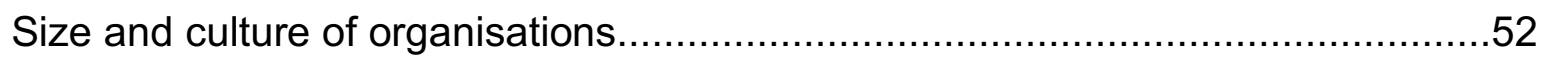

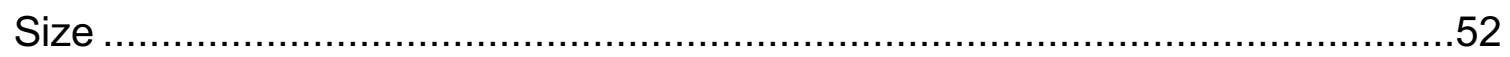

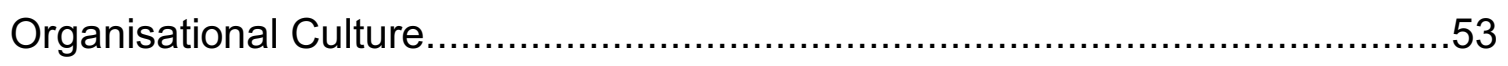




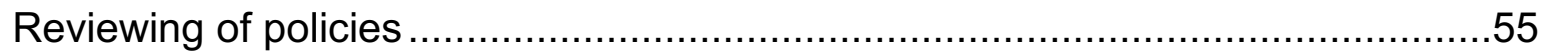

Active reviewing and employee involvement .............................................56

The role of Human Resources professionals ................................................ 57

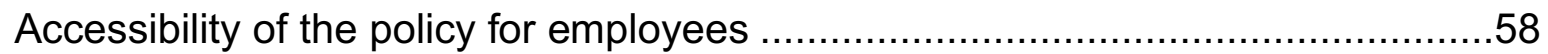

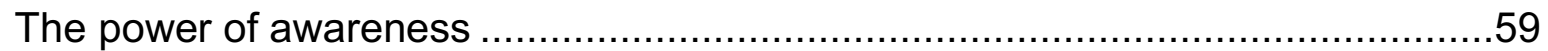

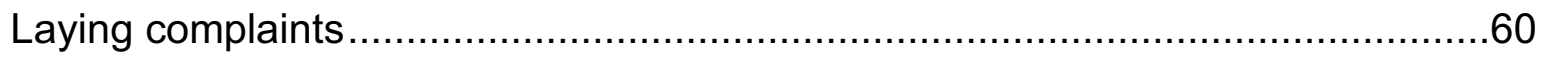

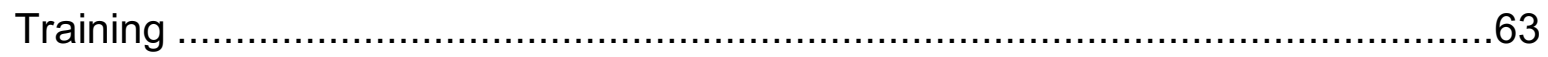

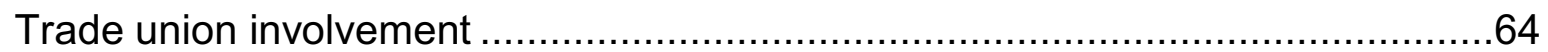

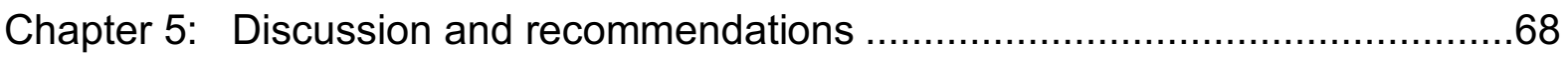

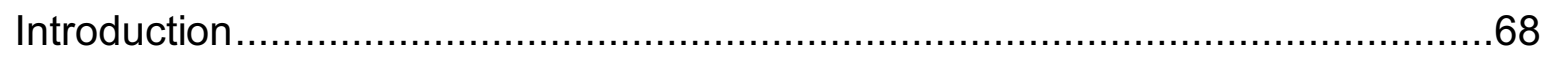

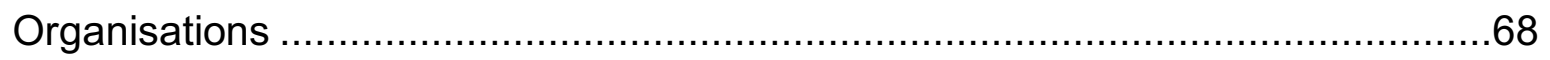

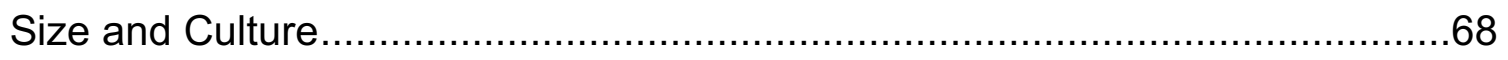

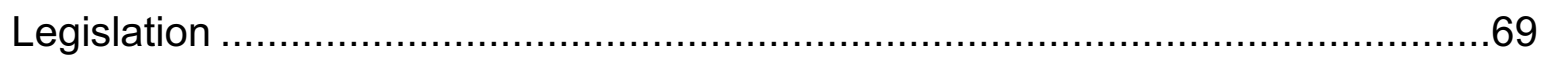

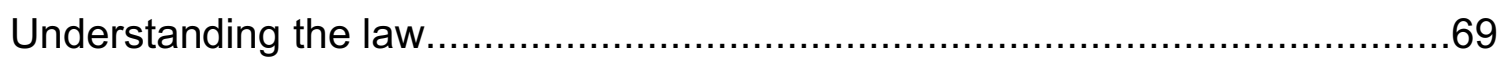

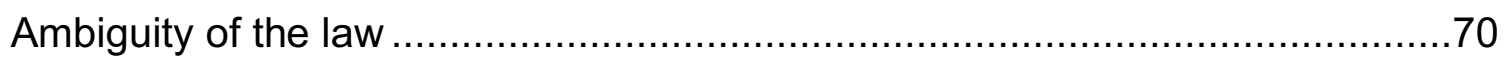

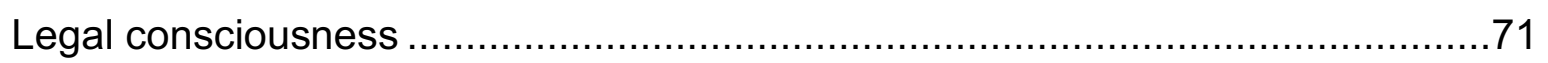

Awareness of the law and laying complaints ......................................... 72

The endogeneity model and sexual harassment policies and procedures ...........73

The strategic role of consultants and trade unions ..................................... 75

The role of Human Resources consultants ................................................ 75

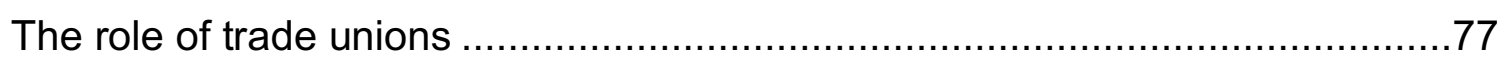

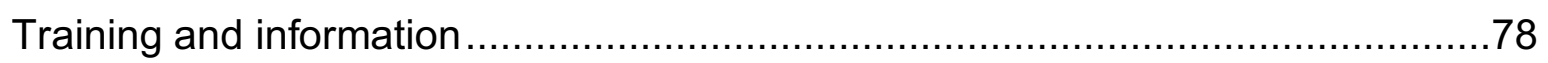

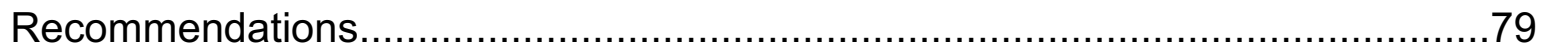

Chapter 6: Conclusion, limitations and future research............................... 80

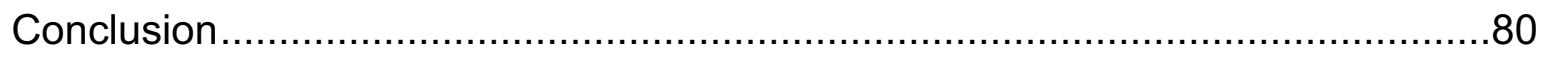

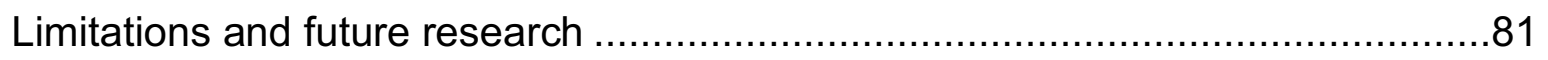

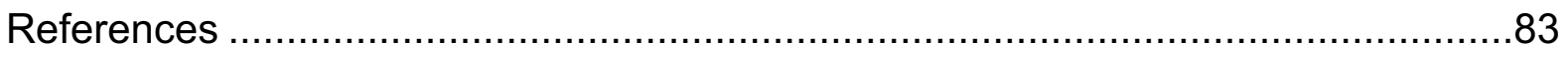

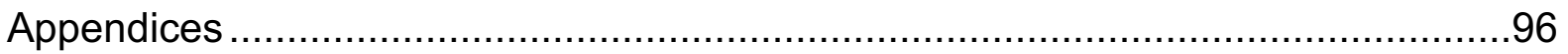

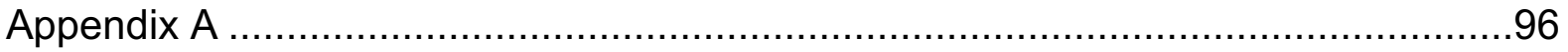

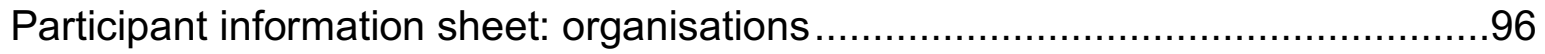

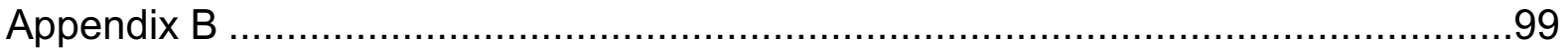

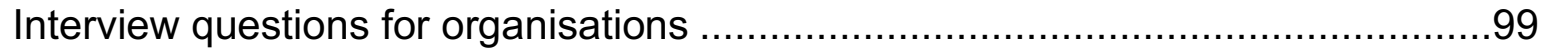

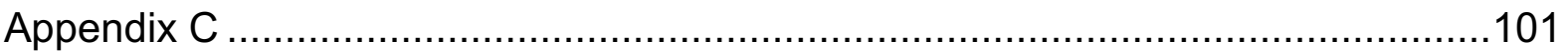

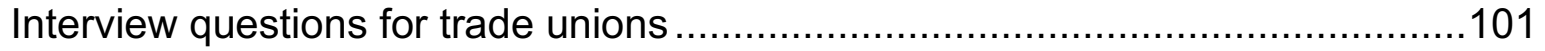


Appendix D

103

Research consent form

103

\section{List of Tables}

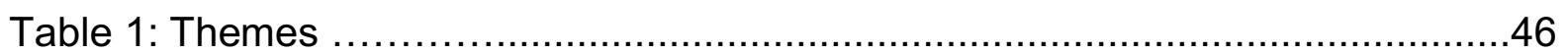

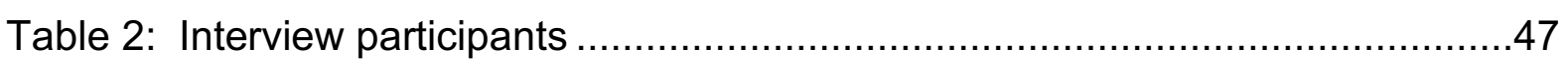

\section{List of Figures}

Figure 1: Sexual Harassment Map from the World Policy Analysis Center ( 2017) 


\section{Introduction}

Sexual harassment in the workplace is prevalent worldwide and has a devastating effect on victims with severe long term psychological and even physical manifestations like headaches, depression and post-traumatic stress disorder (Gutek \& Koss, 1993) The recent sexual harassment allegations against Harvey Weinstein and the resulting MeToo movement, has highlighted the high prevalence of sexual harassment internationally, as well as how many people were afraid to lay complaints for various reasons.

To fully understand sexual harassment it is important to understand where it started, how it is defined, as well as the roles that different genders play. The term sexual harassment was first coined in 1975 by the three activists, Lin Farley, Susan Meyer, and Karen Sauvigne, in the United States of America (Brownmiller, 1975). Their observations of sexual harassment between male and females drove them to become the driving force behind the increasing public awareness of sexual harassment in the United States of America. Eighteen years later, New Zealand incorporated a detailed definition of sexual harassment into section 62 of the Human Rights Act 1993. Stating that sexual harassment is a "violation of human rights" and can include sexual words, gestures and/or pictures.

Worldwide there is a drive towards sexual harassment awareness but there are still many countries which do not have anti-harassment policies or policies which focus only on women. Research by the World Analysis Centre (2017) has shown that 68 countries do not have any anti-harassment legislation in place, leaving employees with no legal route should they experience sexual harassment in the workplace as is seen in Figure 1. 


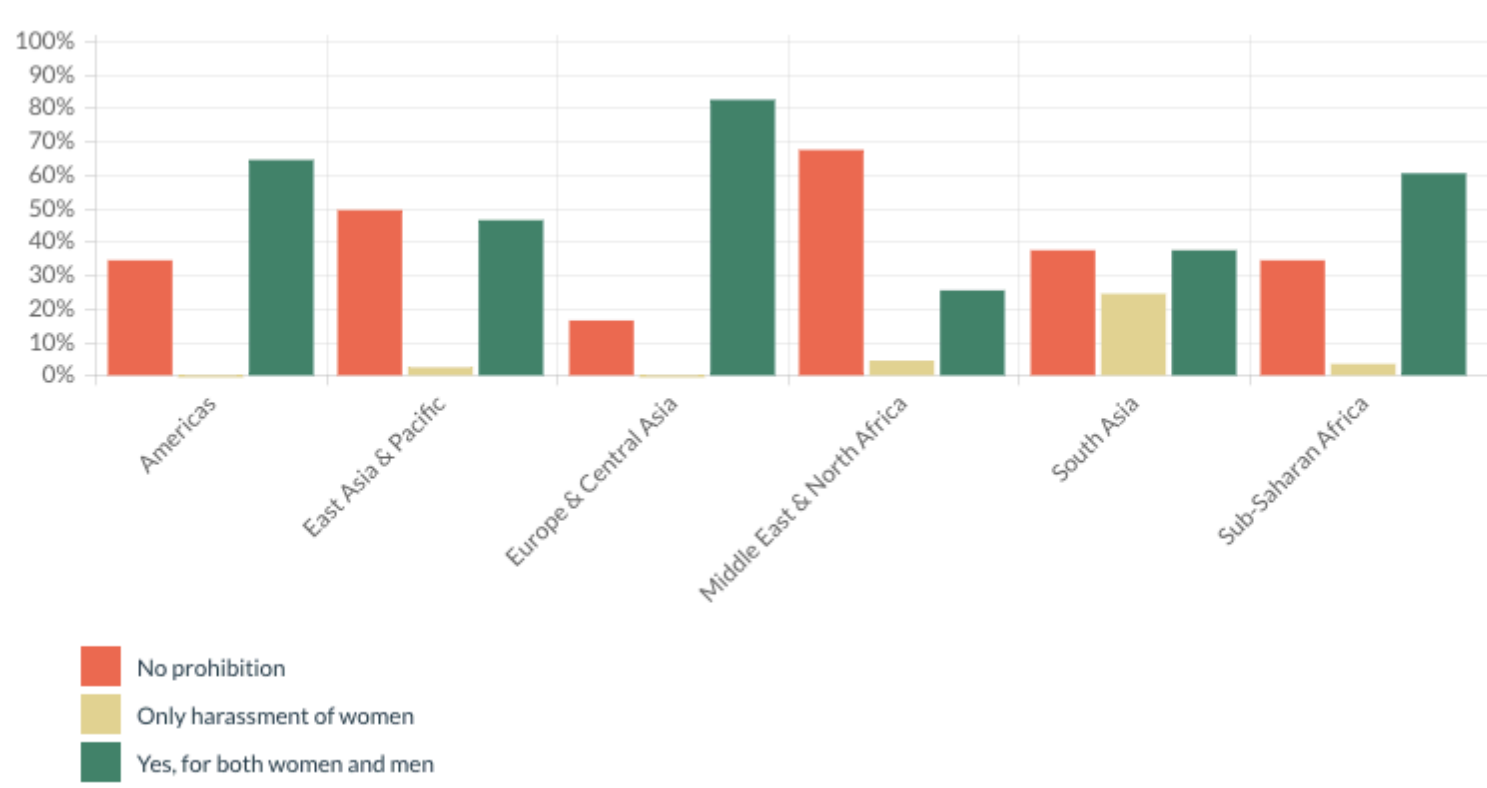

Figure 1: Sexual Harassment Map (World Policy Analysis Center, 2017)

Traditionally sexual harassment is seen as harassment by a male to a female and a traditional interpretation of sexual harassment defines it as a form of systematic discrimination which results in dominant male structures benefitting over women (Cairns, 1997; Connell, 1987). Although these definitions focus on male to female harassment, research has shown that men are increasingly experiencing sexual harassment from women as well as same gender sexual harassment (DeSouza, Solberg \& Elder, 2007), but as the focus of this thesis is not on the gender issue related to sexual harassment, the male/female relationship will be referred to. The term sexual harassment does not necessarily mean sexual desire but includes the act of preserving a male dominated environment where sexual harassment is used to keep this masculine power within the male groups, and to dominate women who do not fit into the expected norms held by the group (Lee, 2000; Robinson, 2005). This dominating environment is as a whole prevalent in environments which have high ratios of unequal genders with high numbers of males in power positions, they use this power to enforce the norms and force employees to act and behave in certain ways in order to stay within the boundaries of the accepted gender norms (McLauglin, Uggen \& Blackstone, 2012; Popovich, \& Warren, 2010). 
How these norms are formed and maintained are often influenced by the broader external practices which define sexual harassment occurrences. The media plays a significant role in this in that it does not focus on unequal gender environments during sexual harassment cases but rather focuses on employee and their individual deviant behaviour (McDonald \& Charlesworth, 2013). Eyre 2000, found that many organisations use policies and procedures which individualise sexual harassment thereby taking away the focus on the wider inequalities within the organisation or the organisation's culture, making sexual harassment the individual employees' fault and not the organisation's responsibility. This shift of blame means that many employees are unwilling to make use of sexual harassment policies and procedures due to fear of repercussions within, as well as outside the organisation (Gutek \& Koss, 1993) which could ultimately cost them their jobs.

Adding to the unwillingness to complain, sexual harassment has fallen out of focus in the last decade in New Zealand. This is directly related to the cessation of awareness campaigns like the sexual harassment prevention week held in 2001 by the Human Rights Commission, which had the main aim of increasing sexual harassment awareness and prevention (Human Rights Commission, 2001).

There are several measures which can increase the willingness to report and the effectiveness of sexual harassment policies in organisations, external third parties like trade unions and Human Resources consultants could be involved in the drawing-up and implementation processes. The third parties place pressure on the organisations to comply with legislation (Dobbin \& Kelly 2007; Edelman, Uggen, \& Erlanger, 1999) and ensure the legal consciousness of the sexual harassment law in the organisational and legal environments by ensuring that employees are aware of their rights.

Although New Zealand has a large body of research which has researched the effects of sexual harassment actions on employees in various industries, and how it impacts on individual and organisational motivation and performance (Choi \& Dickson, 2009), to date there is very little understanding about how legal compliance to the sexual harassment legislation does not necessarily ensure effective management and reduction of the behaviour. Over the last decade there have been several cases in New Zealand heard in the Employment Relations authority as well as the Human Rights tribunal involving sexual harassment have raised questions as to the level of 
ambiguity in the wording of the legislation, as well as to which extent organisations themselves interpret, implement, and manage sexual harassment in the workplace environment.

\section{Aim of the Research}

The overarching aim of this study is to fill a gap in the New Zealand literature which is to investigate whether the sexual harassment legislation is being understood, implemented and monitored in organisations effectively. The research is divided into the following aims:

- Investigate the impact that the sexual harassment legislation has on the compliance measures of organisations.

- Assess if sexual harassment legislation is ambiguous and if this has an effect on how it is implemented into organisational policies and procedures.

- Investigate the role that third parties play in the implementation and management of sexual harassment policies in organisations in New Zealand.

- Contribute to the endogeneity model by Edelman and Talesh (2011), by focusing purely on the sexual harassment legislation in New Zealand. It will explore how the endogeneity model and legal consciousness of employees and experts can have an effect on the understanding of sexual harassment law, and then changing and implementing these into codes of conduct in a New Zealand context.

\section{Thesis overview}

The thesis begins by exploring the sexual harassment theories, looking at the gender theories and workplace culture impact on sexual harassment in the workplace in Chapter 1.

This is followed by literature around the endogeneity model. It specifically examines how organisations implement ambiguous laws in order to be seen to be complying with the regulations. The organisations then alter the laws slightly while still abiding by them, in order to make them fit in with the organisational culture and managerial 
objectives. It then looks at how these alterations are reabsorbed and implemented into the legal system via organisational best practice, third parties and rulings on cases.

Chapter 1 further looks at the legal consciousness of individual employees, and how this consciousness of the laws within the cultural and social environment affects how individuals perceive the law and its purpose. It further examines how the disuse of a specific law and the corresponding application and information of a new but similar law within an organisation can lead to it not being used.

Chapter 2 covers the legislation of sexual harassment, particularly how New Zealand developed this legislation and how it is implemented today. This chapter further looks at the way that policies and procedures are implemented in organisations and if these are effective in stopping sexual harassment.

Chapter 3 details the methodology used for the research as well as containing the design of the research. The questions were designed to investigate how the organisations, trade unions and third parties interpret and implement the sexual harassment laws in the organisations, if these policies work in practice and if they believe there are any difficulties with the legislation. A qualitative research design was used with an emphasis on an interpretivist paradigm to obtain rich data and provide a better understanding of the relationship between the sexual harassment legislation and the policies implemented by organisations. The result of the interviews was an in-depth understanding of how the participants interpret the sexual harassment legislation.

Chapter 4 presents the findings and themes from the analysis of the interview data. A discussion of the themes from the findings with reference to the literature and the objectives of the study, as well as recommendations is in chapter 5 .

Finally, chapter 6 contains the conclusion, limitations and areas for future research. 


\section{Chapter 1: Literature review}

The literature review is divided into four parts, the first is a summary of the New Zealand research and the theories of sexual harassment in organisations, the second looks at how sexual harassment laws have been implemented into organisations focusing on employee fear, training and information. The third part focusses on the endogeneity model which shows how ambiguous laws are implemented into organisations in order to be seen to comply with the legislation. These compliance measures are then absorbed into the law through good practice policies and the cases heard at various authorities.

The final part looks at the legal consciousness of employees and what they perceive their rights to be regarding sexual harassment legislation and policies within the organisation.

The conclusion summarises the gaps in the literatures this study aims to fill.

\section{Summary of New Zealand research}

Sexual harassment research over the last ten years has emphasized the prevalence of sexual harassment in the workplace and the sexual harassment laws themselves, there is very little which focusses on these points within a New Zealand context. A considerable amount of literature has been published on the effects and reasons for sexual harassment in the workplace (McCann, 2005; McDonald, 2012), focussing on industries like hospitality and service where sexual harassment is highly prevalent and often accepted (Calvasina, 2005; Eaton, 2004; Poulston, 2008; Waudby, 2012; Williams, 2003; Yagil, 2008), education especially in tertiary institutes (Jones, Boocock, \& Underhill-Sem, 2013), manufacturing (Handy, 2006) as well as women in the police force (Brough \& Frame, 2004; Chan, 2013; Hyman, 2000). All the research has defined sexual harassment as it is understood in the New Zealand legislation, how it is interpreted by the employees and the actions they took to overcome the harassment whether they were legal or personal, however, there is no research which looks at the correlation between sexual harassment legislation and the implementation of policies and procedures within organisations in New Zealand, particularly focusing on the endogeneity model by Edelman and Talesh (2011), which suggests that there 
is a relationship between law and the implementation of the law at an organisational level This study builds on and contributes to this work and will incorporate the theory of legal consciousness focusing on the sexual harassment law in New Zealand as a case study.

\section{The theories of sexual harassment in organisations}

Over the two decades several main theories explaining the reasons for and the outcomes of sexual harassment in the workplace have been developed. While some concentrate on the feminist gender-based perspective, several take into consideration the impact that the organisation itself has on sexual harassment behaviour.

\section{Workplace culture}

The research into the workplace culture showed that the structure and the embedded culture of the organisation has a deciding impact on the behaviour of the employees. Denison (1996, p. 624), defined workplace culture as a whole as "the deep structure of the organisation which is rooted in the values, beliefs and assumptions held by organisational members", this linked in with previous research by Fitzgerald, Swan and Fischer (1995) who found that sexual harassment is more prevalent in organisations where the behaviour is tolerated and part of the workplace culture, they further found that organisations with high sexual harassment behaviour culture have limited availability to harassment remedies and they are less effective, showing that the greatest barrier to an effective anti-sexual harassment environment is the culture of the organisation itself. Bumsted and Boyce (2005) and Clayton (1997) expanded the research even further and looked at how the environment itself can have a direct influence on behaviours in an organisation, adding that the environment selects against, removes or reinforces cultural practices. This environment can be within the organisation where the active practicing and living of sexual harassment policies plays a fundamental part in its effectiveness, when the organisational culture through tolerance and behaviour does not do this, the policy becomes a written document with no power. The external environment elements like what the law and society accepts have a direct influence on the practices within the organisation and the resulting consequences of these practices and whether they are implemented or not. 
There is a large body of research which investigates how work culture and tolerance to sexual harassment by employees and the environment leads to increased levels of sexual harassment behaviour and decreased reporting. Chamberlain, Crowley, Tope and Hodson (2008) found that four aspects of work culture have great importance to the prevalence of sexual harassment behaviour and the levels of reporting: the solidarity of co-workers, high levels of solidarity and a harmonious workplace result in lower levels of sexual harassment and increased willingness to report, whereas high workplace anonymity and very physical work results in increased tolerance to sexual harassment behaviour and reduced reporting. The characteristics of the employment itself further have a link to increased sexual harassment behaviour and complaints. Reduced sexual harassment behaviour has been found in organisations which have good support structures from superiors and co-workers as well as better promotion chances for the employees than other organisations. It has further been found that there are fewer instances of sexual harassment in more structured formal environments (Mueller, De Coster, \& Estes, 2001) as employees are more aware of the reporting structure and the policies available to them, the employees further felt that the organisations take better care of them and show more genuine concern (Timmerman \& Bajema, 2000) than informal work environments (O'Hare \& O'Donohue, 1998).

Working environments which are tolerant towards sexual and demeaning behaviour, do not see this behaviour as sexual harassment as it has become a norm within the workplace and is part of the culture (Folgero \& Fjeldstad, 1995). This normalisation of sexual harassment behaviour leads directly to a decrease in reports, not because the incidents have decreased, but because the behaviour is so tolerated that the victims do not see the point of complaining (Williams, 2003). Organisational scholars have found that this tolerated bad behaviour leads directly to an aggressive working environment, which includes sexual harassment behaviour, bullying and incivility between co-workers (Lim \& Cortina 2005; Montgomery, Kane, \& Vance, 2004; Welsh, 1999). Of particular interest in this regard was a study by Lim and Cortina (2005) who found that a large number of the women in their study who had experienced sexual harassment had also experienced bad behaviour like rudeness and condescension in some form, showing a direct link between the two behaviours. 
While it is important to understand how the workplace culture and behaviour condone sexual harassment behaviour it is important to understand why employees are not making use of ant-harassment policies or legislation. O'Hare and O'Donohue (1998) found that there is a significant positive link between the employees within an organisation being aware and informed about sexual harassment policies and procedures, and the incidents of self-reporting of sexual harassment behaviour, but it has also been found that the majority of women will not report a sexual harassment incident due to the fear that they will not be taken seriously, that the harasser will not be punished and that they will then retaliate against the employee by taking away their employment (Pierce \& Aguinis, 1997). It was found that organisations who proactively and effectively enforce sexual harassment policies and procedures generally take a zero-tolerance stance and include harsh sanctions for sexual harassment offences which act as a deterrent to sexual harassment behaviour and promote reporting by victims., (Bell, Quick, \& Cycyota, 2002; Gruber 1998; Gruber \& Smith, 1995; Mueller, De Coster, \& Estes, 2001). Although the zero-tolerance approach together with official complaint procedures, results in a strong reduction in the environmental forms of sexual harassment within the workplace, it does not necessarily reduce the number of personally directed sexual harassment which can take place outside the workplace (Gruber, 1998).

Based on the literature, it is clear that organisational culture and the working environment play a large role in the prevalence and acceptance of sexual harassment behaviour by employees, and that the success of sexual harassment policies is heavily dependent on a zero-tolerance culture where sexual harassment policies are enforced consistently promoting a reporting environment.

\section{Gender context}

Although this thesis primarily looks at the correlation between the legislation and the implementation of sexual harassment policies and procedures in organisations, it is important to note how gender plays a part in sexual harassment, and how particularly women will change their behaviour in male dominated environments. It is traditionally assumed that sexual harassment is experienced only by women from men, but studies by DeSouza, Solberg and Elder (2007); Lee 2000; Waldo, Berdahl and Fitzgerald 
(1998) show that this is not necessarily the case. Sexual harassment can be experienced by any person who challenges or does not conform to the masculine norms found in a specific workplace or social environment regardless of gender.

In addition to the environment and the culture of the organisation, research has also shown that an uneven sex-ratio, job status, overly bureaucratic procedures and size of the organisation can lead to negative differential power dynamics in the organisations (O'Hare \& O'Donohue, 1998; Timmerman \& Bajema, 2000). As women often hold lower positions within organisations they are more vulnerable to sexual harassment due to differential worker power (Welsh, 1999), but conversely research by Quinn 2000 as well as McLaughlin, Uggen and Blackstone (2012) found that women in more senior positions are more targeted for sexual harassment behaviour due to their power and status.

The concept of gender context focuses on the nature of the job and the prevalence of one gender over the other in an industry or workplace (Fitzgerald, Swan, \& Fischer, 1995), Hertzog, Wright and Beat (2008), refer to this as the sex ratio of the occupation or workplace. This is found in occupations which are seen as having a typically masculine or even feminine environment. In New Zealand the nursing and care industry is seen to be a typically female environment with construction as a typically male environment. The sex ratio can result in certain behaviours not being classified as sexual harassment (Welsh, 1999) and being accepted as the norm within the industry or the organisation. For example, in environments which are mainly masculine, women especially will avoid formally defining a behaviour as sexual harassment and will not lay a grievance to avoid feeling "out", to be seen as incompetent or risk their jobs (Collinson \& Collinson, 1996).

Cairns (1997) further suggests that women are silenced through another mechanism called patriarchal socialization. With this mechanism the woman is always seen as "other" to the male norm and women do not have the same sense of entitlement as men. This leads to women being reluctant to name the action because they do not believe that what they experienced was real or even that they contributed to the situation. Research shows that women use more passive and indirect ways to react to sexual harassment incidents, by ignoring the behaviour, avoiding the harasser or turning the behaviour into a joke (Gutek \& Koss, 1993). Many women decide to 
respond passively in an attempt to maintain a calm working environment and relationship with the harasser, Baker, Terpstra and Larntz (1990) referred to this behaviour as the traditional passive, relationship-oriented feminine behaviour which women are more drawn to and makes it difficult for women to complain about sexual harassment behaviour even if there are policies in place. An alternative feminist theory suggests that particularly younger women try to distance themselves from being seen and named as a target of sexual harassment when something happens within the workplace (Wear, Aultman, \& Borges, 2007). Further, Cortina, Lonsway, Magley, Freeman, Collinsworth, Hunter and Fitzgerald (2002), suggest that in an attempt to avoid any disadvantages or perceived preferences which may stem from being a woman, younger women are trying to be actively gender neutral.

\section{The implementation of the sexual harassment law in organisations}

Although the organisations are expected to comply with sexual harassment legislation, it is not compulsory and there are no legal guidelines in New Zealand about how this legislation should be implemented into their policies and procedures and codes of conduct and by whom.

Researchers have found that in an attempt to reduce sexual harassment incidents, organisations are asking Human Resources and external consultants to implement human resources policies which inform victims of their rights, what the procedures are if the employee feels victimised and whom the employees should contact in the case of an issue (Bergman, Langhout, Palmieri, Cortina, \& Fitzgerald, 2002; Reese \& Lindenberg, 2004). Although these policies explicitly targeting sexual harassment are shown to reduce the cases of sexual harassment (Poulston, 2008), it is unclear whether having a policy in place is enough of a deterrent to sexual harassment behaviour on its own or if other aspects like training and information play a significant role too. Employee fear to complain may mean that sexual harassment complaints decrease but that the incidents still occur. 


\section{Employee fear}

Most employees choose not to make a formal complaint about sexual harassment whether it is through internal procedures or through outside organisations like the Employment Relations Authority (McDonald, 2012). Some estimated 5-30\% of employees file formal complaints within the organisation but only $1 \%$ will proceed with legal routes (Fitzgerald, Swan, \& Fischer, 1995) with the remaining being resolved in internal mediation processes. When a formal complaint does occur, it is often when the employee has reached a point where the discrimination is affecting their ongoing employment. Reasons for not reporting incidents of sexual harassment include retaliation, job loss, self-doubt and not wanting to be seen as a victim, no or limited information regarding their rights and access to external support organisations like trade unions (Gutek \& Koss, 1993).

Further, targets of sexual harassment in small organisations are less likely to report the incidents as the harasser is often the owner and they will rather adopt passive responses like avoiding the harasser (Knapp, Faley, Ekeberg, \& Dubois, 1997). This unknown number of unrecorded cases in New Zealand, whether it is because of nonreporting or the confidentiality of mediation processes, highlights a restriction in available data to measure the effectiveness of sexual harassment policies and procedures implemented by organisations and legislation.

\section{Training and information}

While there are fewer cases of sexual harassment being raised in organisations with sexual harassment policies, it does not automatically mean that there are fewer incidents although this might be the case. Hertzog, Wright and Beat (2008), showed that organisational policies are not enough to deter sexual harassment behaviour on their own. Training programmes for management and employees have been shown to increase employee satisfaction and reduce turn-over and legislation costs (Choi \& Dickson, 2009). As well as training, Calvasina (2005) found that employer response rates are an important part in reducing sexual harassment in the workplace and complaints should be dealt with immediately and confidentially by fully qualified staff. Conversely, Prattern and Lovatt, (2005) argue that having qualified personnel to deal 
with sexual harassment cases is not always possible and smaller organisations often find it impossible to employ extra help.

These studies show that training and having qualified personnel to deal with sexual harassment cases, is an essential tool for organisations to utilise to manage this behaviour. However, due to the severely limited research carried out on this topic in New Zealand, there is no guideline which organisations can use to train their staff and aid in the prevention of sexual harassment in a specifically New Zealand context. Overall, there seems to be some evidence to indicate that laws and guiding principles for policies help to raise the awareness of sexual harassment and give a legal redress for the employees, but they cannot be seen in isolation. Organisational policies and procedures play a vital role in the recognition, prevention and management of sexual harassment incidences, through providing rules and norms and shaping how organisations interpret and implement the law. Organisational policies will differ depending on the geographic location, size and nature and there are no universally accepted procedures for implementing policies in New Zealand. Large organisations with several hundred employees will have higher standards and tend to implement the policies and procedures, whereas small companies and family businesses will have lower or even no standards. There is limited research in New Zealand which explores the relationship between the size of an organisation and implementation of effective codes of conduct and the direct effect on sexual harassment cases within each one.

\section{Endogeneity model}

New Zealand organisations are obliged to comply with employment legislation this is typically done through the implementation of codes of conduct and policies and procedures within the organisational structure. McCann (2005) found that organisations respond to laws by producing policies and procedures in line with the laws, Edelman, Fuller and Mara-Drita (2001); Edelman, Uggen and Erlanger (1999), found that organisations translate laws to best suit their organisational interests, these are then adopted by the individual players within the organisation as well as eventually being assimilated back into the law. This area of research is founded on the idea that the laws are formed outside the organisations and that the organisations then 
implement these laws strategically in order to comply with these laws (Gunningham, Kagan, \& Thornton, 2004).

Although the majority of organisations in New Zealand follow the employment legislation, it is unclear if the organisations interpret the laws and implement them to suit their interests, one of which is purely to be seen to be complying with the law. This is particularly unclear when focusing on sexual harassment legislation. Further research has shown how ambiguous laws, and the lack of practical guidelines on how to transform these into everyday organisational practice, mean that organisations face an uncertain legal and organisational environment (Dobbin \& Kelly, 2007; Edelman, 1990; Sutton, Dobbin, Meyer, \& Scott, 1994). The organisations respond to this uncertainty by implementing compliance measures (Hegewisch, Deitch, \& Murphy, 2011). Ambiguity is defined as "Where a word or phrase is capable of two or more meanings and which, in the context, raises doubt or uncertainty as to which is intended" (Duhaime's Law Dictionary, n.d). New Zealand's sexual harassment law is ambiguous in several instances as phrases can be interpreted differently depending on perception and the situation, this will be covered in more detail in Chapter 2.

Edelman and Talesh (2011) further found that once the organisations have implemented compliance measures, they become a part of the organisational and legal field logics, becoming widely accepted as legitimate measures, thereby influencing the judicial and legislative field logics. This process of re-assimilation is called endogeneity and it follows several steps:

First, when faced with ambiguous laws, the organisations will adopt formal structures to symbolise compliance. Krawiec (2003) referred to this as "cosmetic compliance" and these compliance measures are symbolic legal structures which show attention to the law and thereby legitimacy for the organisation.

Second, the organisations strive to preserve their managerial discretion and authority by attaching existing organisational goals and values to the compliance (Edelman, 2004). This allows the organisations to maintain a level of flexibility in the compliance structures (Gilad, 2014). As the laws regulating organisations tend to be highly ambiguous, the organisations are forced to look to the legal environments for guidance on how to comply with these laws. The legal environments of organisations become 
the organisations' platform for collectively constructing the meaning of compliance to the law.

Edelman, Fuller and Mara-Drita, 2001 as well as Edelman 2004, defined legal environments as, "the areas where legal and organizational fields overlap; they are the law-related norms and practices that diffuse in organizational fields, which are derived in part from legal fields." These legal environments help the organisations form their ideas of what is right, fair and proper when complying with ambiguous laws.

Third, compliance structures are imitated by other organisational entities. These forms of compliance acquire a rationality which is taken for granted and quickly become institutionalised (Edelman, Abraham, \& Erlanger,1992).

The final step is a blurring of organisational and legal fields, and the organisational values and procedures infiltrate the legal logic through judicial rulings and legislation. (Dobbin \& Kelly 2007; Edelman \& Talesh, 2011).

Although these studies offer important insights into the how organisational and legal fields have a direct impact on each other, it is based on research conducted in the USA and is not directly about sexual harassment. It can therefore not be generalised to sexual harassment laws and organisations within New Zealand. This illustrates a need to investigate the endogeneity model and to explore if this model can be used within a New Zealand context.

\section{The strategic role of third parties in endogeneity}

A number of studies have found that third parties like professionals, trade unions and industry bodies, play a role in the endogeneity process by placing pressure on organisations to comply with legislation (Dobbin \& Kelly, 2007; Edelman, Uggen \& Erlanger, 1999), or by highlighting conflicting or contradictory compliance issues and thereby triggering institutional change (Edelman, Uggen, \& Erlanger, 1999).

Often the third parties have an interest in the way that organisations comply with laws. Whereas personnel experts will implement human resources policies and procedures as a rational way to limit legal actions and reduce negative press for the organisations (Dobbin \& Kelly, 2007; Edelman, 1990), they also construct the understanding of compliance with ambiguous laws to align with their professional goals, thereby 
ensuring the demand for their services (Dobbin \& Kelly, 2007; Edelman, Fuller, \& Mara-Drita, 2001; Edelman, Uggen \& Erlanger, 1999).

In the 1990's, personnel experts and trade unions, not legislation or courts, were the driving force behind sexual harassment grievance policies being implemented into organisations in New Zealand. These third parties argued that the compliance measure would reduce the legal risk for the organisation, resulting in more and more organisations implementing grievance procedures (Dobbin \& Kelly, 2007).

As the momentum of sexual harassment awareness decreased in New Zealand over the last decade due to the loss of power by the trade unions, the driving force has reverted back to the legislation and courts. It is unclear how much of an impact the third parties, for example trade unions still have in changing the codes of conduct in larger organisations who have little need for their advice. Especially when they incorporated the sexual harassment policies into the codes of conduct years ago and have not had a reason to change the processes.

\section{Trade union involvement}

During the 1980s in New Zealand women unionists had successfully pushed for additional clauses to be put into their employment contracts, these clauses were specifically designed to protect female employees from sexual harassment (Hill, 1994). With the end of compulsory unions in 1991, these clauses were also abolished and resulted in an associated decrease of sexual harassment protection in the workplace (Hill, 1994; Oxenbridge, 1997).

There is very little research on the role which trade unions play in the implementation or effectiveness of sexual harassment policies and procedures in New Zealand. The union membership in New Zealand has dropped from 34.1\% in 1991 to $15.2 \%$ in 2015 , there has been a further decrease of the number of unions from 181 in 2003 to 121 in 2015 showing a marked decrease in power in the organisations (Blumenfeld, 2015). The loss of power since the abolishment of the compulsory unions has meant that they concentrate on the bigger and more important issues for their members like equal pay for similar jobs, minimum or living wages for their members and bullying, and has 
resulted in decreased attention to other issues like sexual harassment (Oxenbridge, 1997).

There is no research in New Zealand which investigates if involving the trade unions in the drawing up and management of sexual harassment documentation has an impact on the number of sexual harassment cases in organisations. There has been some research on the role that trade unions play in the reduction of sexual harassment behaviour in South Africa, this is mainly due to a strong union membership, with $27.4 \%$ of the workforce part of a union in 2015 (Statistics South Africa, 2016).

In 2017, the International Labour Organisation (ILO) published a series of cases which reflect how the active involvement of the trade unions has helped to decrease the number of sexual harassment cases in the agricultural sector in South Africa.

Since 1997, the South African Commercial, Catering and Allied Workers Union (SACCAWU) has actively enforced an anti-sexual harassment campaign consisting of education, training and information material like posters and leaflets for their members and their employers. They further drew up a model sexual harassment policy for the workplace and this has been effectively used in various organisational policies and codes of conduct throughout the country. The female employees in the agricultural sector in South Africa experience high levels of sexual harassment due to their precarious work conditions where they will lose their jobs if they complain about being a harassed. SACCAWU actively represented their members and promoted the implementation of their sexual harassment code within the sector, this has resulted in noticeable reduction in sexual harassment cases over the last three years. SACCAWU and other unions in South Africa further realised that women are less likely to report sexual harassment incidents to men and have consequently included as many women as possible in their health and safety training courses as well as ensuring a well-balanced representation of gender within the union representatives (International Labour Organisation, 2017).

This case shows that although sexual harassment was not completely eradicated from the agricultural industry, the use of education and information within the organisations 
and with the members, has a direct effect on the number of sexual harassment cases reported.

\section{Legal consciousness}

When laws fall into disuse because individuals do not make use of their legal rights by either ignoring or rejecting them, the ability of the law to shape opportunity and meaning is reduced and its power lessens (Marshall \& Barclay, 2003; Quinn, 2000). Sexual harassment is extensively regulated in New Zealand in the Employment Relations Act 2000 as well as the Human Rights Act 1993. These regulations give employees the legal rights to remedy inequality and discrimination using the grievance policies and procedures put in place by the organisations, but many employees are not able or willing to take the steps put in place by the organisations whether this is due to fear or lack of information and training.

Legal consciousness looks at how ordinary people make sense of the world around them, it is how they interpret and experience the laws to avoid or use the law and its meanings (Merry, 1990; Silby, 2008). It is primarily a study of society and culture and does not concentrate on the laws themselves, making it a study of subjective experiences of individuals rather than the law itself and its influences (Cowan, 2004; Ewick \& Silby, 1998). Legal consciousness further looks at how laws still retain power within institutions even when there is a gap between how the laws are implemented in organisations and the original legislation (Silby, 2008).

It is important to note that legal consciousness is produced in people's actions as well as what they say (Cowan, 2004; Ewick \& Silby, 1998). Within organisations, everyday situations can influence how the laws are understood and even changed, through conversations with co-workers and supervisors or conflicts within the workplace, the understanding and wider understanding of the law is influenced and even altered (McCann, 1994). In New Zealand, many employees decide against laying formal sexual harassment grievances and choose to handle the situation themselves or have conversations with co-workers and friends (Williams, 2003). This could change the way the law is understood and interpreted. 
On the other hand, legal consciousness also takes into consideration how people do not think about the law and simply accept the laws and take them for granted on a daily basis (Nielsen, 2000).

The theories of legal consciousness discuss how the perceptions of sexual harassment are formed and the likelihood of resulting responses (Blackstone, Uggen, \& McLaughlin, 2009). Whether or not employees understand that they are being discriminated against with sexual harassment is a difficult concept which is formed by legal consciousness. Felstiner, Abel and Sarat (1980) referred to this as "naming, blaming and claiming". The employee has to see and understand an action to be discriminatory or detrimental (naming), then another person or entity has to be held responsible for the action (blaming) and lastly the employee must look for a remedy (claiming).

There is a gap within the New Zealand context, when it comes to looking if Human Resources experts, Human Resources professionals and trade union representatives lose legal consciousness of a law once it has been a part of the organisation's policies for a longer period of time and has not been changed. The sexual harassment legislation in New Zealand has not been changed significantly since the revised Employment Relations Act in 2000, and many sexual harassment policies and procedures where implemented shortly after this revision. This raises the question whether the sexual harassment legislation has fallen out of legal consciousness purely because it has remained largely unchanged and the polices have not been revised, or has the sudden focus on bullying taken attention away from sexual harassment?

The increase in awareness since the high-profile allegations against producers and prominent men around the world, has led to a reawakening of sexual harassment awareness among women. This "Weinstein effect" has resulted in a large number of women worldwide sharing their sexual harassment experiences over social media on Twitter under the hashtag \#MeToo. As this is a current occurrence there is no research which has studied the effect this sudden high level of awareness of sexual harassment due to social media will have on sexual harassment reporting and management. 


\section{Summary}

In New Zealand, the Employment Relations Act 2000 as well as the Human Rights Act 1993, have several sections making provision for sexual harassment. This legislation is expected to be incorporated into codes of conduct in organisations thereby reducing the occurrence of sexual harassment incidents and giving the employees an avenue to lay grievances if necessary. The reality is that only a small amount of grievances laid progress to the Employment Relations Authority, most being dealt with internally, this lack of concrete data makes it almost impossible to ascertain the effectiveness of sexual harassment legislation and policies. Although there is research which focuses on the definition and reasons for sexual harassment in the higher risk industries in New Zealand like hospitality, manufacturing, construction and the police force, there is no research which explores how the interpretation of legislation by organisations can directly impact and even change how the law is understood and used on a day to day basis in business.

\section{Chapter 2: $\quad$ Legislation}

\section{New Zealand sexual harassment legislation}

This chapter looks at how the sexual harassment laws were implemented and why in New Zealand. It covers the definitions of sexual harassment and how the feminist movement has helped to evolve the laws, it further looks at the Employment Relations Act 2000 and the Human Rights Act 1993 and how these Acts address sexual harassment today. It further explores the newest Health and Safety in The Workplace legislation and its link to bullying in the workplace.

\section{A human rights issue}

Sexual harassment is classified as a human rights issue in New Zealand and it is deemed to be illegal not only in the workplace but in all areas of public life.

The original Human Rights Act was passed in 1977 and with it the Human Rights Commission was formed. They were charged with the duty of ensuring that New Zealand complies with its Human Rights commitments. At the time, New Zealand had committed to the Universal Declaration of Human Rights (1948), the International 
Covenant of Economic, Social and Cultural Rights (1966) as well as the Covenant on Civil and Political Rights (1966). All the treaties contain sections stating that discrimination based on sex within the workplace is illegal, but none of them specifically mention sexual harassment or give a definition of it. This lack of a definition became apparent as a problem when the first sexual harassment case was heard in New Zealand at the Human Rights Commission in 1985. (New Zealand Human Rights Commission, 2001). The lack of a clear definition of sexual harassment at the time meant prosecutors first had to prove that gender was the main reason for the discrimination and that there had been no other reasons.

The Human Rights Act was amended in 1993 bringing it in line with the employment laws in New Zealand, as well as including several new human rights commitments, among which was the UN Convention on the Elimination of All Forms of Discrimination against Women. The Human Rights Act 1993 finally defined sexual harassment separately to harassment and made it illegal in New Zealand society.

\section{Definition of sexual harassment}

In section 62(2) The New Zealand Human Rights Act 1993 sexual harassment is defined as any action which is sexual in nature and can include sexual words, gestures and/or pictures. The act further states in section 62(2)(a)(b) that the action has to be unwelcome or offensive to the person and repeated or of such a nature that it has a detrimental effect on the employee's employment. Interestingly, the unwelcome or offensive action does not have to be conveyed to the harasser under this Act, but it does have to be conveyed under the Employment Relations Act 2000.

The Human Rights Act 1993, and the later revised Employment Relations Act 2000, make two types of sexual harassment illegal:

1. Quid pro quo which is the demand for sex in exchange for favourable treatment (Mackinnon, 1979; Williams 2003), and

2. Hostile environment which is defined as "use of language (written or spoken), visual material or physical behaviour of a sexual nature. To subject an employee to unwelcome or offensive behaviour which is repeated or is significant enough to have a harmful effect on an individual's employment, job performance or job satisfaction." (Employment Relations Act 2000, section 108(1). 


\section{The Employment Relations Act 2000}

As sexual harassment is seen as a violation of human rights as well as a workplace issue, it is necessary to understand both Acts and what makes them different from each other.

The New Zealand Employment Relations Act 2000 contains two sections which specifically focus on sexual harassment.

\section{Section 108(1)}

This section of the Employment Relations Act 2000 makes it unlawful for an employer or representative to directly or indirectly ask an employee for sexual intercourse, sexual contact, or other form of sexual activity by promising or implying that they will receive preferential or detrimental treatment if they do not comply.

It is further unlawful to use language (written or spoken), visual material or physical behaviour of a sexual nature to subject an employee to unwelcome or offensive behaviour (whether or not that is conveyed to the employer or representative) which is repeated or is significant enough to have a harmful effect on an individual's employment, job performance or job satisfaction.

- Should this section apply then the employee may lay a complaint about the sexual harassment behaviour to their employer or a representative of the employer.

- Under subsection 2, upon receiving a complaint the employer or representative must inquire into the facts of the complaint.

- If the employer or representative finds that the behaviour took place, they must take whatever practicable steps to prevent a repetition of the behaviour.

Remedies or practicable steps are stated under section 123(d) and includes the transfer of the person, disciplinary action, rehabilitative action or any other action that is necessary to stop further harassment. 


\section{Section 117 Sexual or racial harassment by person other than employer}

This section is particularly relevant to industries who have high levels of third-party sexual harassment for example hospitality and nursing (Williams, 2003).

(1) This section applies where-

(a) a request of the kind described in section 108(1)(a) is made to an employee by a person (not being a representative of the employer) who is in the employ of the employee's employer or who is a customer or client of the employer; or

(b) an employee is subjected to behaviour of the kind described in section 108(1)(b) by a person (not being a representative of the employer) who is in the employ of the employee's employer or who is a customer or client of the employer; or

(c) an employee is subjected to behaviour of the kind described in section 109 by a person (not being a representative of the employer) who is in the employ of the employee's employer or who is a customer or client of the employer.

(2) If this section applies, the employee may make a complaint about that request or behaviour to the employee's employer or to a representative of the employer.

(3) The employer or representative, on receiving a complaint under subsection 2, must inquire into the facts.

(4) If the employer or representative is satisfied that the request was made or that the behaviour took place, the employer or representative must take whatever steps are practicable to prevent any repetition of such a request or of such behaviour.

\section{The Human Rights Act 1993}

The New Zealand Human Rights Act 1993 differs from the Employment Relations Act 2000 in that it clearly states that the employer is obligated to provide a safe work environment for the employees during the course of their employment. This means that the employer is liable for sexual harassment if the work environment is offensive or hostile, whether this is allowed by the employer or not.

Just like in the Employment Relations Act 2000, the Human Rights Act 1993, section 62(2) defines sexual harassment as behaviour which is unwelcome or offensive, and 
as in the Employment Relations Act 2000, there is no clarification in the Act about what behaviour would be classified as unwelcome or offensive

The employer can defend claims by proving that all reasonably practicable steps have been taken to ensure a safe work environment. There is no clarification what steps would be classified as practicable.

The failure to specify what actions would be classified as "offensive and unwelcome", could make it difficult for the average person without any legal background to interpret the law. Not all organisations are large enough to employ permanent Human Resources staff who can interpret the meaning of abstract laws and this could lead to misinterpretation. Further, the organisations could take a tick-box approach by implementing the law purely to be seen to comply and thereby lend them a measure of credibility.

Although otherwise very similar with regards to sexual harassment, there are subtle differences between the Employment Relations Act 2000 and The Human Rights Act 1993, which have an effect on who makes use of the Act.

- The Employment Relations Act 2000, section 117(2) stipulates that in order to show sexual harassment, the employee has to show that the employer or representative of the employer was aware of the behaviour. Most importantly, an employee cannot lay a complaint against a co-employee under this Act.

- The Human Rights Act 1993, section 62 does not make it necessary for the employee to show that the employer knew about the sexual harassment behaviour. The responsibility lies with the employer to have taken practicable steps to prevent sexual harassment taking place. Under this Act it is also possible for an employee to lay a complaint against a co-worker. Further, the definition of "employer" is very broad under this Act and can include "employees" of independent contractors and unpaid workers.

Although there is extensive legislation prohibiting sexual harassment in New Zealand, the proceedings used to resolve these issues are not contributing to the elimination of the problem. A large amount of sexual harassment cases are resolved at the mediation stage within the organisations themselves, at the Employment Relations 
Authority and the Human Rights Commission. As the outcome of the mediation remains confidential it is not known exactly how many cases of sexual harassment are still happening in the New Zealand workplace.

There is limited research investigating if the sexual harassment legislation and the policies within the organisations have any impact on the amount of cases being heard within organisations or by the authorities, leading to the assumption that the law is working but without being able to prove or support the fact that these laws are effective in the workplace. This non-reporting, even on just the amount of cases being heard and resolved, makes it difficult to measure whether the implementation has worked in the long term.

\section{When is it sexual harassment? Ambiguity and the law.}

Although anti-harassment law is covered in two separate Acts, organisations and employees are still faced with the challenge of understanding if an action was actually sexual harassment or not, as neither the Employment Relations Act 2000 nor the Human Rights Act 1993 states exactly what action is unwelcome and offensive, as this is often based on perception.

Rudman (2016) found that there are several aspects which mediators, organisations and employees can take into consideration when trying to answer this question:

\section{Context}

Context plays a crucial role in deciding whether an action was of a sexual nature or not. This is particularly important when it is difficult to determine whether an action was explicitly sexual in nature, for example when an employee bumps into another employee while walking down a corridor. Repeated actions could show sexual harassment behaviour but isolated incidents would not objectively be seen as sexual in nature (Rudman, 2016).

However, far too little attention has been paid to what actions would be considered to be of a sexual nature, as is seen in the Newman $v$ Taxi Lease Ltd t/a The Plant Place [2014] NZERA case, a hard slap on the bottom was not seen as to be of a sexual 
nature by the commissioner, if a slap on the bottom is not sexual in nature then the question arises what is?

\section{The objective versus subjective test}

The objective versus subjective test is used to determine whether an action was offensive. The objective test is what a reasonable outsider would think and whether or not they would perceive the behaviour to sexual harassment. In this case the intentions of the person using the language is not taken into account. The subjective test is whether the complainant found the action to be offensive or not, in this case the harasser would have to take into account the employee's sensibilities as there is no reasonable person test for this in New Zealand (Rudman, 2016; Williams, 2003). For example, the case which was heard by the Human Rights Tribunal, where a sex worker found the sexual language from her employer to be offensive but not that from her customers (DML v Montgomery [2014] NZHRRT 6).

\section{Harmful effect on employee employment}

It is difficult to determine whether there was a harmful effect on the employee's employment, job performance or satisfaction as many employees, especially in small organisations, are reluctant to lay a personal grievance of sexual harassment as the employer themselves are often the harasser. The employees further fear reprisals and job loss (Rudman, 2016). In this position the employee will often decide to handle the situation by avoiding the harasser in the workplace or resigning from their position in order to avoid confrontation (Knapp, Faley, Ekeberg, \& Dubois, 1997).

\section{Coercion and annoyance}

The Complaints Review Tribunal made a distinction between 2 categories of sexual harassment in, coercion and annoyance (Proceedings Commissioner $v$ Sahay and Anor [1996] CRT 9/95 (Decision 34/96). Coercion is when the harasser attempts to coerce the employee with job benefits to grant sexual favours. Annoyance is the sexual behaviour which is hostile and offensive but is not directly linked to any work benefit or detriment (Rudman, 2016). 
Although these considerations are helpful in clarifying difficult situations, they do not remove the ambiguity of certain words and actions in the legislation which can be interpreted in two different ways depending on the person and the situation. This does not make the law any easier to understand or interpret for employers, employees and legal institutions.

\section{Cases}

The following cases from the Employment Relations Authority show how the considerations by Rudman (2016) have been implemented in practice.

\section{Newman v Taxi Lease Ltd t/a The Plant Place November [2014] NZERA Auckland 481}

The case of Newman v Taxi Lease Ltd t/a The Plant Place November [2014] NZERA Auckland 481, shows that the ambiguity of the law can affect the outcome of cases.

The applicant claimed that the respondent had slapped her on the bottom and that she had found this inappropriate and unwelcome, and she was shocked by the behaviour. She resigned from her job the following day, citing the slap as the reason and laid a sexual harassment claim against the employer. The respondent claimed that he had slapped her because she had been cheeky about his hat and that it was meant as a "fun slap" and was not intended to be anything more. The authority member agreed with the respondent and considered that in the context it was a "fun slap" and not harassment and found in favour of the respondent. Further the applicant had to pay the respondent $\$ 5000$ compensation.

According to the Employment Relations Act 2000 section 108(1)(b) the definition of unwelcome behaviour is behaviour which is "not solicited or invited and the person finds undesirable or offensive at the time". Although the context may have been a response to a joke between the parties, the fact remains that the applicant felt the action was unwelcome and she felt offended by it. The commissioner further used section 108(1)(b)(iii) of the Employment Relations Act 2000 which defines sexual harassment as: 
(iii) "physical behaviour of a sexual nature - directly or indirectly subjects the employee to behaviour that is unwelcome or is sensitive to that employee (whether or not that is conveyed to the employer or representative) and that, either by its nature or through repetition, has a detrimental effect on that employee's employment, job performance, or job satisfaction."

This together with the subjective basis that the respondent claims that he did not intend it to be offensive, the authority member found the slap not to be sexual harassment.

The ambiguity of the wording in the section, in particular the words "unwelcome" and "offensive", makes it difficult even for an expert to decide which physical behaviour is sexual in nature. The applicant herself stated that the behaviour was unwelcome and severe enough for her that she experienced a detrimental effect on her employment in that she resigned.

\section{D v E Ltd 05 August [2013] NZERA Auckland 338}

In 2013 the Employment Relations Authority made a contentious decision when it found that an Auckland woman had been partially at fault when she claimed to have been sexually harassed in her workplace, saying that 'she had not done enough to ensure her own safety'.

The woman worked for a food service company and resigned after having only worked there for two months, stating that four workmates had sexually harassed her numerous times.

The authority member, agreed that the woman had experienced sexual harassment but said that "I find it unlikely that the employees concerned sought deliberately to harass or otherwise upset D. However, I find it likely that their banter and joking behaviour went too far." The harassers had made comments about her appearance and had allegedly made offers to "service her needs". In another incident a co-worker had slapped her on her bottom while she was climbing up a ladder.

The employee had not complained about this behaviour to the company and the authority member therefore rejected her personal grievance claim, as she did not give the company the opportunity to stop the actions. The authority member stated that: "The employee did not display the distress which I accept she felt, so that there was 
nothing in her observed reactions to alert [her bosses] to the possibility of a problem. She is intelligent and educated. She understood the behaviour was unacceptable and amounted to sexual harassment."

The authority member further found that the employee had an obligation as per her employment agreement and that because she had not told her employers about the incidents, she had not taken "all practicable steps to ensure her own safety at work" and she had breached her employee obligations.

In this case the question of whether the behaviour can be seen to be of a sexual nature is objective and whether or not the harasser intended the action to be offensive. The authority member felt that the harassers had not intended their actions to be offensive even though there were several incidents. The subjective test of whether the employee found the behaviour to be offensive or not was not addressed by the authority member and neither was the detrimental affect which the behaviour had on the employee causing her to resign.

As in Newman v Taxi Lease Ltd t/a The Plant Place [2014] NZERA Auckland 481, the employee was told that she should have informed the company of the incidents so as to give them the opportunity to remedy the situation. This is not explicitly stated in the Employment Relations Act 2000.

Employment Relations Act 2000 states in section 108(1)(b)(iii) that: "- an employee is sexually harassed in that employee's employment if that employee's employer or a representative of that employer- directly or indirectly subjects the employee to behaviour that is unwelcome or offensive to that employee (whether or not that is conveyed to the employer or representative) and that, either by its nature or through repetition, has a detrimental effect on that employee's employment, job performance, or job satisfaction."

The highlighted sentence shows that the employees did not have an obligation to inform the employer or representative of the behaviour. 


\section{Kumar v Icehouse (NZ) Ltd [2006] ERNZ 381 (EmpC); L v M Ltd [1994] 1 ERNZ 123 (ET)}

In the case of Kumar v Icehouse (NZ) Ltd [2006] ERNZ 381, the applicant claimed that the respondent had brushed up against her several times and made her feel uncomfortable. The behaviour in this case was seen as borderline and the authority member again used the deciding aspects.

It was found that action occurred in front of a witness, who claimed that the accuser laughed in reaction and did not take the action seriously. There were further no words or gestures to accompany the action and this meant that in the context it was seen not to be sexual in nature. Further, the objective versus subjective test was used in this case and the commissioner found that the applicant had not reported earlier incidents in writing and they could therefore not be taken into consideration and there was therefore no proof of repeated actions.

These cases show that the ambiguity of the word "unwelcome" and "offensive" pose a significant problem for all parties involved. It seems that unless there is a clear objection to overtly sexual behaviour or sexual advances, any complaints about ambiguous or less overt sexual behaviour may make it almost impossible to prove as sexual harassment due to a lack of supporting cases on what is classified as "unwelcome" in ambiguous cases.

\section{Penalties}

The penalties for acts of sexual harassment are not substantive enough in New Zealand to motivate harassers to stop the behaviour. Even for the organisations the penalties are far too low and they are not enforcing zero-tolerance sexual harassment policies because of this. This is particularly evident in the following cases from the Employment Relations Authority and the Human Rights Tribunal.

At the Employment Relations Authority the average compensation awarded to sexual harassment claimants between 2014 and 2016 ranged from $\$ 5000$ (Newman $v$ Taxi Lease Ltd t/a The Plant Place 24 November [2014] NZERA Auckland 481) to $\$ 7500$ (Singh v Palaniammah Ltd and Ors [2015] NZERA Wellington 84) and $\$ 7000$ (Owen $v$ The Chief Executive of the Department of Corrections [2016] NZERA Auckland 253). 
In the case MacGregor v Craig [2016] NZHRRT 6, the Human Rights Tribunal awarded Macgregor $\$ 120000$ after Craig claimed MacGregor had breached the settlement agreement. This compensation was unusual as the Human Rights Commission usually awards between $\$ 5000$ and $\$ 10000$.

A landmark case in Australia in 2014 saw a dramatic change in the compensation awarded to sexual harassment claimants. In Richardson $v$ Oracle Corporation Australia Pty Ltd [2014] FCAFC 82, Ms Richardson was awarded $\$ 100000$ by the Full Court of the Federal Court in Australia. Prior to this decision, the compensation in Australia was very similar to New Zealand and ranged between $\$ 12000$ and $\$ 20000$. Several cases which have followed since this decision have shown that this high compensation is becoming the norm and have even risen as high as $\$ 330000$ (Collins v Smith [2015] VCAT 1992; 256 IR 52).

Whether these high penalties will act as a deterrent against sexual harassment behaviour has not yet been determined, at very least it causes a significant financial loss to the harasser or the organisation.

\section{Health and Safety at Work Act 2015}

On 4 April 2016, the new Health and Safety Act 2015 came into effect, it repealed the Health and Safety in Employment Act 1992. The Act states that "employers must take all practicable steps to ensure employees' safety, including protecting employees from harmful behaviour such as harassment and bullying."

If an employer does not deal with harassment or bullying issues in the workplace, it could result in grievances or legal liability for the employer. The Act additionally makes employees individually responsible for their behaviour in the workplace.

Under the Health and Safety at Work Act 2015, employers are responsible for removing risks so far as is "reasonably practicable" in the workplace. If it isn't possible to remove the risk completely, it "must be minimised so far as is reasonably practicable."

WorkSafe New Zealand defines 'reasonably practicable' as doing what is reasonable to ensure health and safety in circumstances, taking into consideration what a reasonable person would do in a given situation. Just like in the Human Rights Act 
1993 the term "reasonably practicable" remains ambiguous under this act, there are no guidelines about what measures to put in place and the organisations are left to decide for themselves what to do.

\section{Sexual harassment and bullying}

Sexual harassment and harassment are covered in the Employment Relations Act 2000 and the Human Rights Act 1993, there is no provision for bullying in either Act which prompted WorkSafe New Zealand to publish a good practice guideline called "Preventing and responding to workplace bullying" specifically to target this issue. The guideline includes a detailed definition of bullying, its effects on employees, and how to avoid and deal with cases of bullying in the workplace.

Although the guideline focuses on bullying in the workplace, it can easily be used as a guideline on how to manage other unreasonable behaviour like harassment and sexual harassment, which also creates a risk to the health and safety of employees in the workplace.

\section{The prevalence of sexual harassment in the workplace}

In 2012, the New Zealand Human Rights Commission (NZHRC) filed a report which found that despite the sexual harassment legislation, sexual harassment is still prevalent in many sectors in New Zealand (New Zealand Human Rights Commission, 2012).

What is not clear is why sexual harassment is still prevalent in the New Zealand workforce even though the sexual harassment law has evolved over several decades. It appears that the law itself is not being used and enforced in the workplace, or being effectively policed to ensure that sexual harassment disappears from New Zealand.

\section{Conclusion}

Even though there are sexual harassment laws in two acts in New Zealand, the description of what actions classify as sexual harassment is open to interpretation and dependent on the perception of anyone looking at the action. It is unclear if this ambiguous wording of the sexual harassment law, the complacency of lawmakers and 
employers, together with inaction of employees, is rendering the sexual harassment law ineffective and promoting a tick-box application in the policies and procedures documents. Overall, there seems to be some evidence which indicates a need for additional research to fully clarify the relationship between the organisations and the various sexual harassment laws in New Zealand.

\section{Chapter 3: $\quad$ Methodology}

\section{Introduction}

The following chapter explains the methodology used in the research. It begins with an outline of what qualitative research approach is and why I decided to use this method for this research. The interpretivist paradigm was chosen as it focuses on the understanding of the world from the individual person's subjective experiences. Through the use of semi-structured interviews, the approach looks at the subjective interaction between the researcher and the participants. This is followed by an explanation of how the sample for the study was chosen as well as the interview style. Lastly the method of data analysis is discussed as well as the imitations of the study.

\section{Research paradigm}

This research is based on the constructivist epistemology which states that truth and meaning are created by individuals and their interaction with the world around them. As meaning is constructed, individuals will construct their own different meaning of a phenomenon, even if the phenomenon is the same. This means that multiple, opposing versions of the world or situation can exist (Gray, 2013).

The interpretivist paradigm, which is closely linked to the constructivist epistemology, was chosen for this study. This method aims to generate rich data and thereby gain greater understanding of the connection between the sexual harassment legislation, how it is implemented in organisations through policies and procedures and finally how individual players understand and use these policies and laws. This approach helps to understand the intricate relationship between the legislation, organisations and individual players and explores how these relationships change and evolve over time (Neill, 2006). 
The interpretivist paradigm emphases observation and interpretation, this means collecting information about a subject and then understand this information by making deductions or matching the information by using an abstract pattern (Aikenhead, 1997). The methodologies used are meaning-oriented which means that methodologies like interviewing and observation are used. (Kaplan \& Maxwell, 1994). Themes are developed from themes which arise from the interviews and are not developed in advance before the interviews.

Interpretive research is based on the philosophical base of hermeneutics and phenomenology (Littlejohn \& Foss, 2009).

Phenomenology is based on the theory that we can only understand social reality if we study people's experiences of social reality (Gray, 2013), it focuses on discovering and communicating essential characteristics of certain phenomenon as they really are. It looks at how several individuals will describe the same experience or phenomenon differently (Creswell, 1998). Phenomenology makes use almost exclusively of interviews which are used to gather rich information and represents this information from the research participant's viewpoint, and highlights the individual participant's experiences from their own perspectives

\section{Research design}

Qualitative research was used in this study in the form of semi-structured interviews.

The subject of sexual harassment policies within the organisations is a sensitive topic and it proved challenging to find organisations who would take part in the research. Snowball sampling was used after finding the first organisation which was prepared to do the interview.

\section{Human Ethics}

Due to the involvement of human participants in the research, human ethics approval was applied for and granted under the number 0000023643. Specifically due to the sensitive nature of this topic it was important to note the following:

- All participation was voluntary and the participants could choose to not answer at any point. 
- Consent was gained from the participants before the interview and they were given a detailed breakdown of what the research entails.

- All data is confidential and is stored in secure storage.

- The identity of participants will not be divulged without prior permission and steps were taken to ensure that the identity of individuals and organisations cannot be deduced from the content of the thesis.

- Obligations to the Treaty of Waitangi were upheld.

\section{Snowball sampling}

Snowball sampling is a technique which is often used in qualitative research (Faugier \& Sergeant, 1997). It is used when finding participants to take part in interview becomes a challenge, particularly in hidden populations or when the subject is of a sensitive nature (Heckathorn, 2002; Monette, Sullivan, \& DeJong, 2010).

The identification of possible participants who fit the requirements specific to the research being undertaken requires snowball sampling. After the initial contact with the first participant, they refer other possible participants back to the researcher (Trochim \& Donnelly, 2006; Vogt, 1999).

This study focused on Human Resources professionals within organisations, policy makers and representatives within trade unions, as well as third parties like Human Resources experts and consultants who have an overall perspective of sexual harassment policies within New Zealand. The challenge in recruiting participants for this study lay in the sensitive nature of the subject as well as finding the people who had the relevant knowledge in sexual harassment policies and legislation to be able to answer the interview questions.

The first interview was with a large organisation where the researcher had taken part in a project the previous year. This organisation then referred another possible participant. Each consecutive participant referred another participant to the researcher. 
Participants were sent the information sheet before the interview to read and they were given the same sheet on the day of the interview. One interview was conducted telephonically as the participant was not able to attend a meeting in Wellington. All other interviews were conducted at the organisations themselves.

\section{Interviews}

As this study is of a qualitative nature, interviews were chosen as the data collection method. An interview is a conversation between two people where the interviewer will ask questions which are specific to their research objectives (McNamara, 1999).

Interviews can be conducted in three ways; (1) structured interview, (2) unstructured or open-ended interviews, and (3) semi-structured interviews.

A structured interview uses pre-determined questions and a set of answers from which the participant can choose their responses (Monette, Sullivan, \& DeJong, 2010). This method was not used as the answers would not have delivered the depth of information which is needed for this study.

The unstructured interview is an open-ended conversation using a checklist to ensure that all points are covered (Clark, 2006). This method can elicit a large amount of information which is not relevant to the research and was therefore not chosen for this study.

The method chosen for this study was the semi-structured interview. This method allowed a certain structure to the interview process which stopped it from becoming a conversation, but was still flexible to be able to elicit extra information which was possibly not included in the questions (Gratton \& Jones, 2004; O'Leary, 2005).

Due to the complex nature of the subject the semi-structured interviews had the advantage that the researcher could explain the questions if the participants were not clear on them and new themes could arise because of the data received from the questions. Participants are also more likely to answer questions if there is an interviewer than if they are asked to answer a survey which is why this approach was not used (Monette et al., 2010). The interviews resulted in additional themes surfacing which had not been considered before the interviews and they were then added to the study. 
In this study, there were 11 semi-structured interviews.; 4 trade union representatives, 4 organisations and 3 third party experts. Only eleven interviews were conducted due to time constraints related to the difficulty of recruiting participants.

\section{Research questions}

The interview questions were formulated based on my experiences working in the Human Resources industry and on the literature on the subject. Participants were asked between 12 and 15 questions depending on whether they were organisations, trade unions or third-party experts (see appendix). The interviews were designed to determine if the participant had experience in the sexual harassment legislation as well as to elicit their observations on its implementation in policies and procedures in organisations. The questions then explored the depth of their experience and what experiences they have had with the implementation of the sexual harassment laws within organisations, including how the processes are reviewed and how accessible they are to the employees themselves. Finally, they were asked about any possible difficulties they see with the sexual harassment laws and if there are any developments within their organisations on the subject.

The aim of the questions was to find out how the sexual harassment laws are interpreted and implemented in practice and if the policies which are put in place are effective and accessible to individual employees and whether or not the employees are making use of these.

The interviews consisted of three areas. The first covered the participant's position and the company which they work for. The following questions and the bulk of the questionnaire contained questions about the how sexual harassment policies are implemented in the organisations and the measures taken to review these. The last questions covered the involvement of trade unions and third parties in the implementation of policies in organisations. Included were questions about the sexual harassment legislation and if the organisations/trade unions/third parties see any challenges or developments in their respective areas. 


\section{Participants}

The sample consisted of a total of 4 Human Resources professionals working within organisations, 4 policy makers and representatives within trade unions, as well as 3 third parties like Human Resources experts and consultants in New Zealand. It was important that all of the participants had knowledge and experience of the sexual harassment legislation or the human resources policies and procedures within the organisations they worked or consulted at.

The sample for this study is small and this is often the case in qualitative studies, but the sample size was adequate to obtain rich data for the study without reaching saturation and becoming repetitive (Mason, 2010).

\section{Data collection}

The interviews ran between 15 minutes to 1 hour 15 minutes and were voluntary. The participants could refuse to answer questions or withdraw from the interview at any point. All interviews were audio recorded and transcribed with the permission of the participants.

Some of the participants rushed through the interview sticking very closely to the suggested questions but others seemed to enjoy telling me about their experiences and knowledge about sexual harassment law and policies.

\section{Data analysis}

Qualitative data analysis exposes themes which are found by the analysing, categorising and discussing the collected information by the researcher (Huberman \& Miles, 2002).

The interviews were transcribed verbatim which helped me to better understand the data and start generating themes before the qualitative data began.

Thematic analysis can be used to analyse information using specific codes, Boyatzis (1998) defines thematic analysis as using themes which are related in some way to form codes which can then be used to encode qualitative data. 
There are several ways in which raw data can be coded and categorised. The cutting and stacking method where the transcripts are cut up and placed into relevant themes, this allows for flexibility and phrases and words can be moved as needed (O'Leary, 2003). This technique further decreases bias as the participants become anonymous (Gough \& Scott, 2000).

A further technique is writing notes in the margins of the transcribed documents and then analysing the similarities and themes (Kwortnik, 2003).

A combination of the two techniques was used for this research. During the initial analysis phase, the interview transcripts were read repeatedly and themes noted in the margins. As the analysis progressed several themes and key words like "awareness" and "culture" became apparent and were coded and categorised according to themes. The next stage involved cutting the transcripts and stacking them according to the themes identified during the first stage of analysis. This was beneficial as it made it easy to find the repeated trends and words and match them up with the themes.

\section{Limitations}

Due to the sensitive nature of the research it is possible that the participants in the interview told me what I wanted to hear. A questionnaire may have elicited different and more candid responses from the interviewees, due to a greater feeling of anonymity (Monette et al., 2010). The interpretivist approach is often criticised as being biased due to the subjective nature of the method and the data collection (Myers, 2008). To avoid this during the interviews, I made sure not to lead the answers and avoided contributing my own thoughts to the answers.

The small sample size of only 11 interviewees, all from the Wellington area, limited the generation of generalisable data. This limitation was reduced by interviewing trade unions who are representative of a large number of employees throughout New Zealand and not just in Wellington. 


\section{Chapter 4: $\quad$ Findings}

\section{Introduction}

This chapter explores the results of the analysis of the qualitative data from the interview transcripts. The interviews revealed a large amount of data, unfortunately some of it cannot be used for this research as it was not relevant to the aim of the research, the data which was used was chosen with the research question in mind.

During the analysis process several themes became apparent, these were placed under the three main headings of legislation, organisations and trade unions.

Table 1: Themes

\begin{tabular}{|c|c|}
\hline Legislation & $\begin{array}{l}\text { - Definition } \\
\text { - Understanding of the law } \\
\text { - Bullying vs. Sexual Harassment }\end{array}$ \\
\hline Organisations & $\begin{array}{l}\text { - } \text { Codes of conduct and procedures } \\
\text { - Size and Culture of organisations } \\
\text { - Reviewing of policies } \\
\text { - Accessibility of the policy } \\
\text { - Awareness of sexual harassment } \\
\text { - Training }\end{array}$ \\
\hline Trade Unions & - Union Involvement \\
\hline
\end{tabular}

\section{Participant profiles}

Due to the diverse nature of the participants interviewed this section will be used to introduce the participants interviewed.

All participants are professionals who have direct experience with the implementation of sexual harassment legislation in policies within organisations or in trade unions in New Zealand. Three participants came from Public Service departments with approximately 2,000 to 12,000 employees and one participant from the hospitality industry with approximately 500 employees. All four Human Resources participants hold Senior Human Resources positions within their departments. 
An additional three participants came from Human Resources consultancy organisations, specialising in policies, employment law, advice and support. The four trade union participants represented the larger unions within New Zealand and represented the public, tertiary, retail and banking sectors.

Table 2: Interview participants

\begin{tabular}{|l|l|l|}
\hline Participant & Role & Industry \\
\hline HR1 & Human Resources Consultant & HR Consultancy \\
\hline HR2 & Human Resources Consultant & HR Consultancy \\
\hline HR3 & Legal Expert and Consultant & $\begin{array}{l}\text { Employment Relations } \\
\text { Expert }\end{array}$ \\
\hline HR4 & $\begin{array}{l}\text { Senior Human Resources } \\
\text { Advisor }\end{array}$ & Public Sector \\
\hline HR5 & Human Resources Professional & Hospitality \\
\hline HR6 & Human Resources Professional & Public Sector \\
\hline HR7 & Human Resources Professional & Tertiary Education \\
\hline U1 & Trade union & \\
\hline U2 & Trade union & \\
\hline U3 & Trade union & \\
\hline U4 & Trade union & \\
\hline
\end{tabular}

\section{The legislation}

\section{Defining sexual harassment}

The participants were asked what their policies define as sexual harassment and they all referred to the definition of sexual harassment found in the Employment Relations Act 2000 under section 108(1)(a) and (b). They described the behaviours as "unwanted" and "inappropriate".

When asked if the legislation had changed much, most participants found that the sexual harassment legislation has not changed significantly over the last decade or said they were not sure: 
HR1: I can't recall that it changed much in the last 10 to 15 years...if it has changed I don't think it has changed by much.

HR2: $\quad$ I wouldn't say that it has changed, because I started working after the current employment legislation came into place.

HR7: $\quad$ The legislation hasn't changed significantly over the last several years.

U4: $\quad$ It hasn't changed to my knowledge.

HR3 showed a contradiction in saying that "everyone knows what sexual harassment is and I think there's a greater awareness. You don't hear much about sexual harassment perhaps as you did 10 years ago."

A strong theme which became apparent was that there is a perception of greater awareness of what sexual harassment is, but perhaps a more nuanced view is that the culture has changed and there is a greater awareness of the gross forms of sexual harassment conduct like pinups and wolf whistling. It is not clear if the awareness of the subtler forms has increased.

HR3: $\quad$ Everyone knows what sexual harassment is and I think there is a greater awareness...workplace culture determines a lot about behaviour, not what is written down.

HR2: I think probably the difference is the level of tolerance for behaviour that could constitute sexual harassment, in both employment environments and also society, and things that were probably more acceptable a long time ago, are less acceptable.

HR1: I think society has changed there's much lower tolerance for that sort of thing, organisations are much more modern and up to date and that sort of generation that were I suppose the people who would typically sexually harass are probably much less in the workplace now.

U3: $\quad$ I find that our members are aware of what sexual harassment is and they come to ask us for help if something happens.

One union participant gave an example of sexual harassment behaviour they had experienced during the 80 's when it was still very prevalent in the workplace: "When I 
got up the blokes all whistled. The members would never do that now. It has changed over the years. That horrible pornographic stuff is gone." (U2)

\section{Understanding the law}

During the interviews the participants were divided about whether the law is easy to understand or not, with the participants with a legal background finding it easier to understand than those who did not.

The Human Resources consultants:

HR2: Although the law is intended to be clear and relatively easily understandable for like your small business in New Zealand type situation, the reality is there is a lot of complexity in employment law and, in particular, on how it's implemented. So, it's not just that you can pull up the Act and read it and know everything there is to know; you have to actually, to avoid being tripped up you do often need to get expert advice to understand how case law is evolving, what that actually means in practice, and things like that.

Participant HR1 found that although the law itself was "relatively easy to interpret" but that the case law which has built up around it over the years has made it really hard because "the standard is so high." This was followed by an example of a recent case at a large organisation: "we had a situation recently with a client where somebody was being sexually harassed by a supplier representative of a supplier organisation and we were brought in to basically do an investigation. Now most smaller organisations probably wouldn't want to do that or be able to afford to do that but I think that is being seen as legally the best practice approach and then you've got to be relatively independent from the reporting line and all that kind of thing, that's quite hard for smaller organisations to do."

Human Resources Professionals:

HR5: $\quad$ The law is difficult to read and unless you are a lawyer you use help sites to get to know what's accepted, what's allowed, what's no allowed. There's a few grey areas about perceptions of different people and what 
I feel is appropriate someone else might find completely inappropriate, so there's all those sorts of layers which would warrant the use of help sites. I just want a How To or guideline so I don't have to spend all my time looking for advice.

HR4 found that the legislation was "easy to interpret if you know how to read legislation, but for the average person it might be tricky."

Trade Unions:

U1: $\quad$ The Employment Relations Act is pretty basic.

U3: $\quad$ The sexual harassment part of the law is ok, the problem arises when you have to define exactly what actions are sexual harassment, it's not so clear about the behaviour.

Interestingly, two participants said that the sexual harassment had to occur more than once before it was considered to be harassment "repeated over a period of time" (HR7) and "the action has to happen more than once and over a longer period of time" (U3), this is incorrect and if severe enough, one act can be seen as sexual harassment (Human Rights Act, s. 62(b).

\section{Bullying versus sexual harassment}

Several Human Resources professionals and union participants discussed the difference between sexual harassment and bullying, saying that "the focus is more around the bullying type situation in the workplace, which is possibly more common" (HR7) and that "bullying is much more prevalent in the press and people know more about it". (HR4)

It was also noted that bullying is reported more than sexual harassment, "from where I sit it (SH) is not reported as much, we have more of an issue with bullying. The two seem to morph together. Often workers will lay a complaint about bullying with an element of sexual harassment." (U2)

\section{Organisations}

\section{Codes of conduct and procedures}


Four of the Human Resources representatives showed me the policies and procedures which they have in place in the workplace. The policies have all been in place for a long period of time, the participants were not able to tell me exactly how long as none of them were actively involved in the initial drawing up and implementation of the codes of conduct.

The sexual harassment policies and procedures are all based on the anti-harassment legislation in the Employment Relations Act 2000 and they specifically outline the processes which are available to the employees should they wish to lay a complaint, detailing who the contact person is and how sexual harassment cases are dealt with.

HR7: It's a general harassment but it does specifically have a sexual harassment section that defines what it is and examples of what it could be. Then there's the procedures that you follow, who you need to go to if you think something is happening. Yeah, who you can go to and the process that would be followed, forms to fill out et cetera.

None of the organisations made provision for anonymous complaints, the reasons given were that "it wouldn't be fair on the employee if they couldn't defend themselves against the accuser" (HR5) and it's "difficult to manage such a serious claim if we can't discuss it openly with the accused employee" (HR4).

The participants noted that they all have written policies in place which are closely linked to the legislation

The Human Resources consultants found that the organisations draw up sexual harassment policies to ensure that they comply with the legislation: "there is a tendency perhaps to rely on an expert drawing it up to think that they've covered it off" (HR2), and that the majority of sexual harassment policies are the same, " $90 \%$ of all organisations that we go into have very very similar policies particularly around sexual harassment." (HR1)

"I think most organisations I know would have these policies in place, and they're pretty standard, everyone knows what they say."' (HR3) 
HR3 noted that although organisations have policies and procedures in place it does not necessarily change behaviour: "you can write anything down and that doesn't change any behaviour by having something written in a policy." (HR3)

The procedures open to a harassed employee are different depending on the size of the organisation. In large organisations the employees are encouraged to use several steps before laying an official grievance: HR6 said that their sexual harassment process encourages three stages, the first stage is a "self-help stage" where the employee approaches the harasser directly, the second stage is an "informal intervention" where a manager or Human Resources person takes part in an informal meeting to help resolve the issue. The final stage is to lay a "formal complaint" which entails an investigation by an impartial external person.

HR4 as a large public sector organisation, has a more formal approach and encourages the employee to immediately approach the "immediate manager" and they will decide what action to take.

HR5 also encourages employees to approach their "immediate manager or supervisor" first.

All the organisations stated that the employees can approach "HR for advice" at any stage but that they do encourage their managers to handle complaints as they arise.

HR3 added through an example that this process is difficult for smaller organisations:

"The employee who made the complaint asked that the HR manager wasn't involved or didn't conduct the investigation because she felt that they had a relationship because there was only five people in the management team, and that there wouldn't be any independence. That costs then the small company a lot of money because they've got to pay my fees."

\section{Size and culture of organisations}

\section{Size}

The size of the organisation was a deciding factor given if there were codes of conduct in place. The Human Resources professionals and union representatives all said that 
the smaller the company the less likely that there would be a sexual harassment procedure in place.

HR2: $\quad$ Smaller or newer companies or ones that have started out as a family business or something like that, don't have the same level of documentation that a large company or government department or something would have.

U2: $\quad$ If it's a small company of 10 people they won't have any policies, it's only when something happens then they get one. Or they haven't focused on those policies until they start to grow, and often until something goes wrong, then they realise they should have better things in place. That's quite a common scenario in New Zealand I would say.

U3: $\quad$ The larger organisations tend to have detailed policies, it's the smaller ones which don't feel they need to until something happens.

U1: $\quad$ The public sector organisations all have detailed policies. The larger private sector will also have, it's an image thing.

HR2: $\quad$ Particularly larger places, they want to have things in black and white, and policies and procedures for each thing; other workplaces have a lighter touch, more principles based approach to things where they record key points but then deal with things in a fair and consistent manner.

\section{Organisational Culture}

The participants discussed the culture of the organisations and how this effects the occurrence of sexual harassment. It was agreed that the willingness to complain is a direct reflection on the culture of the organisation.

HR2: $\quad$ Sexual harassment is very much something that is enforced through an individual being prepared to make a complaint about it. So, I think that's why things like culture and tolerance of it is actually more significant in terms of how the enforcement of it comes around, because ... and probably relevant more to the later questions, but I actually think one of 
the biggest issues in here is whether or not you have a culture of being able to speak up and raise an issue of something that you consider to be sexual harassment. So actually, it's the social environment of how it fits in.

HR2: It's not about just having a policy that says sexual harassment is not condoned and these things constitute sexual harassment; I think it's actually about whether you have a culture that doesn't condone sexual harassment.

As a consultant who works across several organisations or varying sizes, HR2 found that generally the policies in the organisations are the same but that the environment plays a part in its effectiveness: "I think that ... many places would define sexual harassment the same but behaviour may differ depending on whether or not you work in an environment that has a lot of sexual type banter around the workplace, versus somewhere that doesn't. So, I think some things that would be completely normal and part of an everyday workplace in one workplace, could be serious sexual harassment in another workplace. Although that said, I don't really think the words on the page are necessarily that different, but it's probably the way in which they are lived and breathed, the extent to which something is an issue, as well."

HR3 discussed how senior managers can influence sexual harassment behaviour, and said that it is not always blue collar environments which are the most obvious places for sexual harassment incidents: "So even in workplaces, professional workplaces, if you've got senior managers who are quite flippant or quite tolerate, or themselves actually behave inappropriately - particularly I think around the use of inappropriate sexual language, then I think that's not uncommon, I've seen really good examples of workplaces that are perhaps quite small or are perhaps quite blue collar or whatever, where they just have an intolerance. They just say, 'That's not what we do. We don't...', you know?."

HR1 found that when they wrote policies for organisations the culture plays a part in the terminology used: "When we are writing policies for clients we try and write them around that organisations' culture so if it is a small tech start-up it will be perhaps two or three paragraphs and we will use language that we wouldn't use in a government 
department, government departments team to be quite formal they like 3 or 4-page policies that are quite legalistic so there's quite a difference there so we do encourage organisations to have policies that work to their culture."

\section{Reviewing of policies}

When asked when employment policies, in particular sexual harassment policies, are reviewed, two Human Resources professionals admitted that they had not been reviewed or changed in a long time, in some cases several years:

HR7: $\quad$ They're quite ... very, very old. Yeah, really old to be honest but then I guess things haven't changed. I mean, they're meant to be done on a semi regular basis. To be honest, it's probably been reviewed, it just hasn't been updated because there hasn't been a need to be updated.

HR6: $\quad$ So, the policy has been in place for a long time and its quite a detailed policy. We had all the policies and procedures reviewed in 2014 and we did a few tweaks and things here and there, but essentially, they have remained the same for a long time.

When asked if they were planning on reviewing the policies in the near future, three Human Resources professionals said that they were in the process of reviewing and upgrading their codes of conduct but not specifically the sexual harassment sections:

HR4: We are looking at our entire policies and procedures documents to ensure that they are up to date and in line with legislation. We are also updating our code of conduct booklet with the aim of making it easier to understand for all our employees. All employees receive this booklet when they start working here.

HR7 said that they were planning on "refining" all the policies and procedures within the next year saying it is "a chance to re-educate and get out there to the employees and remind them."

HR 5 reviews their policies annually to "ensure that they are aligning with legislative changes and to ensure that the procedures are relevant to the organisation, but I have no plans to concentrate on sexual harassment because nothing has changed." 
HR6 said that "it's supposed to be reviewed annually to see if we are still following best practice. That's probably not the case in that one."

Interestingly, HR1 stated that there is a significant difference between the public and private sector in New Zealand when it comes to the review of policies and procedures: "This is perhaps the difference between the public sector and the private sector the private sector will put policies in place and review them when they need to if something has gone wrong and the policy hasn't worked or it's just out of date they'll review them, my experience of the public sector is that for every policy they have in place they typically have a 2 year life span, and so every policy has a review date when it is formally reviewed making sure it is still current and all of that kind of stuff. But something that we often get asked by organisations is to come in and review all their policies and check they are still current usually play around with the word in a little bit."

\section{Active reviewing and employee involvement}

The Human Resources consultants discussed how they are consulted about policies and procedures: "It's more likely that we would review a list of policies or an employment agreement and say, 'you should have some kind of policy to deal with bullying and harassment and things like that'. So, it's more likely that a gap is identified rather than an employer would come and say, yes, please do this for us. It's more likely something that we would need to say, you should do something." (HR2)

HR4 was the only Human Resources professional who was actively involving the staff in the review process: "It is important that the staff understand the codes of conduct and can use them confidently. We ask the staff to give feedback and ideas about the codes of conduct manuals."

The effectiveness of the sexual harassment policies was not measured by any of the participants:

HR6:

We don't really measure the outcomes as such. I mean usually they are ER (Employment Relations) issues so we measure them if it leads to some sort of warning or termination of employment. So, we measure that sort of thing. But we don't really measure anything else from it. 
HR4:

We keep track of any grievances which are laid but we don't actively measure if the policy is effective.

HR7:

How do we know whether they're effective or not? I'm not sure that we do necessarily know

\section{The role of Human Resources professionals}

The interview data showed that when it comes to sexual harassment, Human Resources is mainly responsible for the drawing up and management of policies and investigation of complaints. The Human Resources professionals found that managers and employees largely rely on them for advice but that they encourage employees to go to their managers first:

HR7: $\quad$ People can come to HR at any time, whether it's the manager or an adviser, whoever they feel more comfortable with. Yeah, or they can just go and talk directly to their manager who can then ... I guess they would ultimately come to HR anyway for advice about what to do.

HR4: $\quad$ The employees can go to their manager or if there is a problem they can ask us for advice.

HR1: $\quad$ They empower their managers more so at the moment the default position is on any breach of policy is to go straight to HR but they are basically saying no we want you as the managers to deal with these issues we are empowering you to deal with them here are the policies and processes that tell you exactly how to do it.

The trade union participants said that the Human Resources departments were mainly responsible for the drawing up of sexual harassment policies and procedures in organisations and that they were "rarely consulted" (U2). U3 discussed the negative aspect of this saying that the policies were "difficult for employees to understand" and Human Resources “didn't consult the employees or ask for input about the policies when they were put into place, they just do it their way."

The unions particularly found that Human Resources departments do not help the employees and that they are pushing the employees back to the managers: "The 
sexual harassment policies always speak about different interventions and the employees have to approach their direct managers first, what happens if the manager is the harasser? The employees don't feel supported and that's when they come to the union for advice." (U1)

\section{Accessibility of the policy for employees}

The codes of conduct and policies and procedures are available for the employees in several ways: The staff intranet, print out available in the staff area, a shared drive. "The staff have access to the polices on the intranet and there is a printed copy in the staff area." (HR5)

Only one organisation actively gave new employees a code of conduct booklet as part of their induction, which the new employees had to read, sign and return to Human Resources to be put in their personnel files. The other organisations used a more passive approach saying that employees could easily access the information using the staff intranet or Human Resources information system, there was no way to monitor if the employees have done so.

Of the 4 trade unions, one had a 12-page information booklet about sexual harassment for their members. The booklet defines sexual harassment, identifies actions which are sexual harassment, options if the person has experiences sexual harassment and how to get help. This booklet is actively distributed to the union's delegates during meetings and conferences.

The Human Resources consultants said that they always advised their clients to actively communicate the policies to all the employees within the organisation and that it depends largely on the size of the organisation how this is done: "Largely depends again on the culture of the organisation and how big they are and whether they've got existing policies. When there it is new policy and when you introduce new policies, there's always an education piece that you have to go through with the staff to make them aware of it to make them understand that this is now something that is going to be enforced. In the bigger organisations that is often communicating on multiple levels in different ways, emailing it out, running sessions with staff, putting it on the intranet all of that kind of stuff. In smaller organisations it's often simply an email saying hey guys we're introducing this please read it be aware of it." (HR1) 
"Some organisations that are very big on risk management and compliance like to have all the staff members sign off to say that they have read and understood it which then goes into their personal record." (HR2)

\section{The power of awareness}

The theme of awareness was prevalent during all the interviews, several interviewees said that they had not really thought about sexual harassment over the last years because there were very few cases coming across their paths. They also discussed the impact or awareness on reporting using bullying as an example:

HR2 discussed the influence that awareness of behaviour might have: "If you look at the list of potentially bullying behaviour in the WorkSafe guidelines, it covers a really broad range of things. Whereas sexual harassment is a bit more specific. But it doesn't mean that if sexual harassment had a similar kind of level of awareness brought to it, that it wouldn't become more of an issue. It probably needs to become more of an issue across society in terms of tolerance and acceptability, rather than necessarily just within workplaces I think."

HR7: "There was an awareness- although people label bullying and it may not necessarily be that. But that's something that's more prominent everywhere ... not here, but I mean out there. So that's something that we're focused on making managers more aware of, than the sexual harassment."

The data also revealed that the participants thought it was important for the employees to be actively aware of the policies in the organisations and for them to know them for them to be effective:

HR3: If you asked the average employee if their company had a sexual harassment policy, they'd probably say, 'Oh yeah, well, you know', and if you said to them, 'Well, have you seen it?' they'd be like, 'No'.

HR1: I think is very important with all policies is that when people join the organisation and making sure that it is part of the induction process that they are very clear what all of these policies are and what's expected of them. 
HR3: $\quad$ Catch-up meetings, just choose a different policy and every meeting talk about it. So, it might be bullying one week, it might be the expenses policy the next week, it might be ... but you've got to keep those things relevant and review them as well, which a lot of people just don't.

HR7: $\quad$ That we're looking at reviewing this particular policy and if anybody's interested in providing some feedback into that. We're going to have a meeting and a workshop or whatever, and then just get those interested people together. It's just a good way of staff feeling that they do have some input into what's going on and what's happening.

The participants from the trade unions all noted that the focus around sexual harassment had decreased over the years, participant U2 saying that they "had dropped the ball a bit on sexual harassment" and U3 noted that "the union was discussing re-raising the issue at their annual conference in July 2017'. U1 further said that it had been a "big topic" in the 80's and 90's but that "organisations and unions are focusing more on bullying and employment equity now, sexual harassment has been pushed to the side."

They were not able to tell me if a decrease in complaints was due to increased awareness, organisational culture and environment or due to the policies which had been put into place. None of the participants were able to give me an exact number of sexual harassment complaints within their organisations.

\section{Laying complaints}

The Human Resources consultants and professionals agreed that dealing with sexual harassment cases is tricky and that the employee's perception plays a role in this:

HR1: How we will deal with every complaint of harassment can be quite different. We need to remember that harassment is actually quite how the person perceives it and again there is not one test of harassment yes that's harassment or no that's not because it's different for different people and you have to respect that, and so is how people want it dealt with. If you have to have three or four different approaches that's the 
best way because not everybody will be comfortable with just one versus the other.

HR3: $\quad$ Some people, what you find offensive and what I find offensive are two completely different things, and I think that's the other challenge for a small employer. They might have had somebody there a long time who has worked with someone and never had a problem with them, and then something changes or a new person arrives and suddenly it's like, 'Well, no, I'm not going to ... and they're like, Oh why? What's wrong'. So, it's not easy.

The participants further stated that small organisations will try to manage an alleged sexual harassment complaint but due to the size it becomes difficult:

HR3: $\quad$ When you're trying as an employer to manage that small workplace and both of those employees are valuable resources to you, that's a real challenge for people. Because you can sit down with somebody who's behaving inappropriately and you can give them a bit of a barrel and say they've got to pull their head in or whatever, but you can tell from their body language and everything that they think the whole thing's a bit of a joke.

The interview data further revealed that the participants felt that employees were unwilling to lay sexual harassment claims against people in the organisations for several reasons.

HR2 said that it was due to willingness and organisational culture, "there's a lot of people that wouldn't be willing to make a complaint, either because they don't want to draw it up or because they think that that might be damaging to their career, or for whatever other reasons, that they don't want to make a big deal of it."

HR3: $\quad$ Sometimes people just don't want to go through the process of raising a complaint and things like that, but I also think that part of it ... a lot of it comes from culture and whether or not the company has a culture of, it's okay to ... we don't tolerate this and we want to find out about these things so ... or we'd rather just not deal with it. 
The participants also said that a large reason for not laying a claim was due to being afraid of their harassers as well as the fear of losing their jobs. The point to note here is that the staff did not know what sexual harassment was until they went to an information seminar:

U1: I had a group of 4 Asian administration staff from a big university come to me after a sexual harassment and bullying seminar we ran in 2015 , they said that they hadn't realised that what was happening to them was sexual harassment and they were shocked. They asked for advice but decided against laying a grievance purely because they were afraid of the harasser and they didn't want to lose their jobs.

The participants found that the biggest challenge facing organisations is a lack of knowledge about what to do when a sexual harassment claim is raised by an employee:

HR1: $\quad$ One of the biggest challenges for most organisations facing a complaint or investigation is how the hell do we do this because we've never done it before. It's just not a common thing now having said that it may be that one of the challenges is that a lot of the stuff still goes unreported, people just deal with it in their own way don't make a fuss about it.

HR3: $\quad$ Unfortunately, what happens quite often is people end up leaving and you just reach a confidential settlement with them because it's just too hard. Particularly for smaller businesses, they just think, 'Oh crikey. We're going to get sued. Oh no, this is terrible. It's just easier if we write a cheque and we all forget about it, and we talk to the boys about - don't carry on like that -', you know?

HR2: $\quad$ Often, it's not actually ... the complainant isn't actually looking for the person to be sacked; often it's just, 'I just want this to stop. I just need somebody to take this seriously'. But with sexual harassment, unfortunately I've found by the time someone makes a complaint it's usually things have got pretty out of hand actually.

The trade union participants were concerned with the system as a whole saying that it does not encourage employees to lay grievances. "The system doesn't deal with it 
not just the organisations. The penalties are too low, an unscrupulous employer doesn't mind a fine of $\$ 10000$. And then you lose your job so you are reluctant to lay a grievance" (U2). "The mediation process means that a lot of cases don't go any further, the employee is often so embarrassed and happy to just get it over with, this needs to change" (U1). "The organisations pay the accuser to keep quiet, we really have no idea how many sexual harassment cases are out there actually" (U3).

One trade union representative had found that members on working visas tied to a specific employee were particularly "reluctant to lay a complaint" saying that "if they lose their jobs they lose their visa's and have to go home, they ask for advice but up until now we have never had any of these members lay a claim because they are too afraid of losing their jobs and visas. This is a huge problem, they are essentially modern-day slaves and the system does not support them at all." (U2)

\section{Training}

The Human Resources professionals were asked if they offer any specific training for their employees or managers on sexual harassment they said that "there hadn't been any specific training for a while". Participants HR6, HR7 and HR4 all indicated that nothing specific about sexual harassment had been done but they were aware of it and admitted it needed to be done:

HR7: $\quad$ They probably haven't had specific training for a while. They would have over time, but I can't say in recent times they'd probably had specific training on it. It's probably more if a situation comes up. I mean they do ... they're aware.

HR6: We don't have any other initiatives as such, we are probably going to have some sort of training in the new year, we haven't had training on those sorts of subjects in a long long time and we are aware that we need to profile a few more things. So, it's one of things that people don't talk about much so it will be quite good for us to highlight it next year from a mental health point of view as well and to just sort of highlight that sort of thing. 
HR4:

No, we haven't done anything specifically around sexual harassment since l've been here and there are no plans for it in the near future, the last training we had focused on bullying. We try keep our managers informed but there is no specific training.

Two Human Resources professionals acknowledged that they had sent their managers on training courses. Participant HR5 said that because of the industry they are in, their "managers had taken part in harassment training in 2015 but there's not much training available for sexual harassment training, it's really difficult to find." HR7 further said that their managers had "some training about a year ago" but that it had focused on "harassment and bullying". "I know sexual harassment is quite specific, but there were all those general situations that come up, which again is pretty much the same process." (HR7)

The Human Resources consultants discussed how training is a good tool to raise awareness of sexual harassment, but that the size of the organisation often determined whether this happened or not:

HR2: I do think that training is a very good means of raising that level of awareness. Larger employers in particular, if they have very regimented training programmes and things like that, I think they could easily have a component alone on sexual harassment. I think smaller and medium companies probably don't have a lot of training or awareness sessions in the workplace.

HR3: $\quad$ So, I think that I do spend quite a bit of time trying to help clients upskill their front-line managers in how to manage crude behaviour or inappropriate conduct, and how to jump on it pretty quickly. Or just to ensure that employees know where they can go if they've got a problem and that it is taken seriously - there's at least someone there who will say, right, okay, that's not okay and this is what we're going to do.

\section{Trade union involvement}

When asked what role trade unions have played in the drawing up and implementation of sexual harassment policies within organisations, the participants agreed that they 
had limited involvement. HR1 said that they were consulted but the organisation still "set the guidelines of what was in the policies and procedures" and followed this with an example:

HR1: $\quad$ I can only talk about a recent example we had where we had been doing a project with a large government organisation, we've actually been completely reviewing and rewriting all of their HR policies, we've had to work very closely with the union, the union have a very strong and fixed ideas about what these policies should be and what should be in them and in fact negotiated into the last collective agreement process that there would be certain policies introduced that the organisation didn't currently have so that we had to take account of that in the work that we were doing as well, it was quite interesting because they were adamant that they wanted a separate SH policy whereas part of our brief was to try and simplify the polices as much as possible because they had too many we advocated to have a single harassment policy that basically and what we were trying to do with the policies was keep them simple and basically say that we will not tolerate harassment of any kind whether it's sexual, racial whatever but then we've got separate guidelines that sit behind each policy so there are separate guidelines for $\mathrm{SH}$, separate guidelines for racial harassment, the unions still weren't happy about that but they do have strong role to play they still see $\mathrm{SH}$ as a major issue particularly in the public sector and other industries there will be particular industries where sexism is particularly rife and you know largely male dominated industries and females will get treated a certain way and vice versa so yeah it depends on the industry, depends on the organisation. But yeah, they are very much involved in that.

The professionals and consultants saw the unions role as mainly representative for their members and an advisor when complaints did arise.

H1: I'm not necessarily sure that they (employees) are better informed because of the union, I think they're probably better helped when there is an issue and I think for somebody who is making a harassment claim 
of any type it is a difficult thing to do, so I think if you've got somebody advocating on your behalf that's a good thing.

HR3: $\quad$ The union was really constructive and very supportive of the employee's position and the investigation. And while they represented or supported their member through the disciplinary processes investigation, they certainly didn't stand in the way when they were dismissed, these people. They completely understood the employer's need to ensure that there was a fair investigation and people were safe at work and all those things.

The interview data revealed that the organisations do not feel that the trade unions play a major role in the drawing up and implementation of sexual harassment policies particularly in the private sector.

HR3: $\quad$ Not really, not really. I mean they do in the government but not in drafting policy, not in my experience. In collective bargaining, they will have some input into clauses in the collective, but anything to do with sexual harassment has usually been around a long time so none of that gets reviewed. But in my experience, unions don't influence workplace policy very much at all, no.

Participant HR3 also stated that "Well most of my private sector clients don't have a union presence in their workplace, there's just simply not. Even big manufacturing clients often don't have unions in their workplace, and if they do they're a very small, you know, less than 20 per cent of their workforce will be covered. So, they just don't have that relationship and it wouldn't occur to them to invite a union and have any input into drafting policy - because their review would be 'This is our workplace and these are the rules that we want to establish here'. They just don't see the value."

Participants saw the unions as having diminished numbers and therefore not much power in the private sector. HR3 found that "the union movement is nothing like it was, just in a sheer numbers game, it means that they really only show up for collective bargaining most of the time. Because the rest of the time they're trying to cover so many workplaces now. My experience working with unions would be usually the employer would draft something and the union might review it in terms of a policy. But 
they wouldn't ... and they'd give feedback which would be considered before it was finalised. Yep, but they wouldn't draft it as such."

HR7 was the only participant who said that they ask the trade union for input, but that they only did so only when they felt it was "appropriate" but wanted to maintain a good relationship with the trade union: "We have a good relationship with our union, so yeah, absolutely and certainly if they wanted to, we wouldn't ... we're not against it at all." (HR7)

Participant HR5 said that "trade unions are not present in their business" but instead they make use of "an industry specific advisory body" who have experience in the industry and have a "better knowledge and experience" about their industry.

The trade union participants saw themselves in a role of mediator and advisor: U2 noted that "we do try to mediate before it becomes too serious and if a SH complaint comes up we deal with it and work through it like any other grievance. If we need help we have a good link with other organisations and also the Human Rights Commission and we can talk with them to decide which step is the best one to take."

The trade unions all stated a lack of resources as a barrier to managing and investigating sexual harassment cases in the workplace and training their organisers in dealing with sexual harassment: "Organisers don't get training, because we came through it and we understand it but perhaps it's time to look at it and up our game again" (U1). U2 further said that they have a "resource issue" and are "reactive to sexual harassment rather than proactive because of this."

Two of the trade union participants remembered the use of sexual harassment representatives within the bigger organisations in the 80's and how they effectively helped reduce the incidents of sexual harassment in the workplace:

"These were trade union representatives who were trained in handling sexual harassment issues and anyone could come to them" (U2). "They were the first point of contact for any employees if they felt they had been harassed, unfortunately they don't exist anymore and neither do the sexual harassment information posters which were all over the workplaces, we just don't have the resources. They really helped to inform women about their rights." (U1) 


\section{Chapter 5: Discussion and recommendations}

\section{Introduction}

This chapter will discuss the findings of the interviews in relation to the literature. It will give insight into how the employment legislation is interpreted and implemented into the organisational structures, it highlights how the ambiguous nature of the sexual harassment law has led to a tick-box compliance by the organisations. It further shows how a reduction in the legal consciousness of sexual harassment policies is resulting in a decrease in the use of the policy and forms a barrier in the dynamic movement of the endogeneity model.

It reveals how the influence of third parties, like trade unions and Human Resources consultants, still have a role to play in ensuring the effectiveness of sexual harassment policy and legislation in New Zealand.

\section{Organisations}

\section{Size and Culture}

The culture and environment in a workplace has a direct influence on the tolerance of certain behaviours. The environment selects against, removes or reinforces cultural practices (Bumsted, \& Boyce, 2005; Clayton et al. 1997; Fitzgerald, Swan, \& Fischer, 1995). This was found to align with the study and the Human Resources consultants and trade union participants confirmed that the culture of the organisation plays a large role in how sexual harassment behaviour is perceived and handled. The more tolerant an organisation's culture is of sexual harassment behaviour, the more likely that said behaviour will happen and be ignored by senior staff.

The implementation of written policies and procedures is not enough to stop the behaviour, if it is still condoned by the managers or supervisors the written word has no meaning. The proactive enforcement of the policies which entails the active distribution of the policies to the employees through meetings and information sessions and ensuring that they understand them and is more effective than a policy which is simply sent in an email or put onto the staff intranet. There is no way to measure that the employees have read and understood the policies, this aligns with 
the research from Bell, Quick and Cycyota 2002; Gruber 1998; Gruber and Smith, 1995 as well as Mueller et al., 2001.

The study further aligns with past research by Knapp, Faley, Ekeberg and Dubois, (1997), who found that employees in small organisations are less likely to report sexual harassment incidents.

Targets of sexual harassment in small organisations are less likely to report the incidents as the harasser is often the owner and they will rather adopt passive responses like avoiding the harasser. There is further no one to police if the legislation is being implemented effectively into organisational policies. The lack of guidelines and policing on sexual harassment policies for small organisations in New Zealand, means that the first indication that things are not right is when an incident occurs and there are no processes for the staff to follow.

\section{Legislation}

This study aims to expand the understanding of how organisations understand the sexual harassment legislation and how it has been incorporated into their policies and procedures. The findings reveal that the law is not completely understood and the wording is found to be difficult and ambiguous for the average person, this has led to the law being implemented into policies and procedures solely as a compliance measure. It has further revealed that the sexual harassment sections in policies and procedures have not been changed in several years due to inactivity in the legislation itself.

\section{Understanding the law}

The interviews revealed that the participants have a general understanding of the sexual harassment legislation as it stated in the Employment Relations Act 2000 and the Human Rights Act 1993, but there was some confusion about the number of times an action had to take place with some participants saying it has to happen several times before it is seen as harassment. This is not correct as section 62(b) of the Human Rights Act 1993 states that a once off occurrence can be seen as sexual harassment if it is substantial enough. 
It was also agreed that they all had employment policies and procedures which contained a section about sexual harassment and general harassment in the workplace. This is in line with past research which found that organisations implement policies in order to align and comply with legislation (Edelman, Fuller, \& Mara-Drita, 2001; McCann, 2005).

It was revealed that specifically the sexual harassment legislation has not changed significantly since 2000, when the Employment Relations Act was amended, and due to this the corresponding sections in the policies and procedures have not been changed either.

This research shows that the law is difficult to understand for anyone who did not have a legal background and the lack of guidelines had made it tricky to implement.

\section{Ambiguity of the law}

The sexual harassment law in New Zealand can be defined as ambiguous as it contains "words and phrases which are capable of two or more meanings and which, in the context, raises doubt or uncertainty as to which is intended" (Duhaime's Law Dictionary, n.d). Organisations respond to ambiguous and difficult laws by implementing compliance measures without understanding the law. (Hegewisch, Deitch, \& Murphy, 2011). The result is "cosmetic compliance" (Krawiec, 2003).

The study revealed that, in practice, the intention of certain words in the sexual harassment legislation were difficult to understand for the average person due to their unclear meaning.

The biggest ambiguity revealed in the study was around the perception of an unwelcome action. The participants agreed that what is unwelcome to one person might be completely normal to another, and that it depends on the person's perception of the action, the environment in which the action took place and even personal values. The same was said for deciding whether an action was offensive or not, here the environment and culture of the organisation was cited as a deciding factor. The example of a construction company was given where a woman found a comment about the way she dressed as offensive. This comment may not have been perceived as offensive in a different environment or by a different woman. This aligns to the 
literature by Rudman (2016) and Williams (2003), where the use of the subjective test to decide whether an action was offensive to the person themselves may be helpful in deciding if sexual harassment occurred. But as there is no reasonable person test for this in New Zealand, it is still up to the investigator or authority member to decide which to use and in legal terms the authority member would use the objective test, i.e. what would a reasonable person think?

The Human Rights Act 1993, section 62 and the Employment Relations Act 2000, section 108, both state that should sexual harassment behaviour happen within the workplace it is the employer's duty to take "practicable steps" to prevent repetition of the behaviour. The guide from WorkSafe New Zealand to aid in the preventing and responding to bullying in the workplace uses the same terminology for bullying in the workplace (WorkSafe NZ 2014). Although there is guidance in section 123(d) of the Employment Relations Act 2000 it is still left up to the organisations to decide what is practical in their organisations.

The study revealed that moving a party may not always be practical, especially in small organisations. Further, disciplinary action against the harasser is difficult if they are the owners of a small business and the accuser is an employee (Newman $v$ Taxi Lease Ltd t/a The Plant Place 2014 [2014] NZERA). This was confirmed in the study by trade unions and Human Resources consultants, and they added that small businesses often do not have any policies in place and the employees have no idea how to deal with sexual harassment behaviour if it does occur.

\section{Legal consciousness}

The study shows that the sexual harassment legislation and the corresponding policies and procedures have not been reviewed by legislators or Human Resources practitioners in the last decade. The Human Resources professionals and the trade unions further noted that they had not actively thought about sexual harassment and their policies in several years purely because no cases or very few cases, had been brought to their attention and there was no need to use them.

This aligns with the theory of legal consciousness and how the laws are taken for granted and simply accepted when they are not thought about (Nielsen, 2000) as well as where the compliance measures have been taken for granted and become 
institutionalised (Edelman, 1990). As a result, employees are not making use of their legal rights and the power of the sexual harassment legislation and policies is decreasing (Marshall, 2003; Quinn, 2000).

There is greater emphasis by all parties being placed on the level of bullying behaviour in New Zealand workplaces. All participants have had more experience in bullying cases and have good knowledge of the laws surrounding it. The extensive knowledge was found to be mainly because the bullying legislation has recently been amended and added to the Health and Safety Act 2015 as well as due to the high level of media coverage which has meant that employees are well informed and aware about what classifies as bullying behaviour as well as the actions they can take if it occurs.

\section{Awareness of the law and laying complaints}

According to the study the Human Resources professionals and the consultants found that the number of sexual harassment grievances they have dealt with has significantly decreased over the last 10 years. This decrease was attributed to a decrease in tolerance as a result of the generational change by employees in the workplace. This does not correspond with numbers from the Human Rights Commission, which still deals with approximately 65 cases per year since 2014, this shows that there are still significant numbers of sexual harassment cases but that there is a decrease in cases being reported in the workplace. Further the study confirmed that there are an unknown number of cases which are being settled at mediation level or the employees are paid a settlement amount before it gets to any formal processes.

The study shows that employees are not reporting sexual harassment behaviour due to fear of repercussions and job loss. This confirms previous literature by Pierce et al. (1997) as well as O'Hare and O'Donohue (1998), where it was suggested that women will not report sexual harassment behaviour due to the fear of not being taken seriously and other repercussions. Participants discussed how many employees in New Zealand are unwilling to complain about sexual harassment because the country is so small and they fear that they will harm their career prospects. This was found to be particularly prevalent in Wellington where as participants noted "everyone knows everyone" and careers can be harmed very quickly. 
The awareness of the sexual harassment law and the policies and procedures available in the organisation, plays a significant role in whether employees will lay a grievance or not. A lack of awareness leads to inactivity and a decrease in the consciousness of the law (O'Hare \& O'Donohue, 1998). There was agreement between the participants that the awareness of sexual harassment as a whole has decreased in the last decade and that the focus has shifted to other topics, in particular bullying. One participant noted that bullying has a high level of awareness due to media activity and the WorkSafe guidelines, and that should sexual harassment get the same amount of attention, it could become more of an issue again as people become more aware of their rights again.

It emerged that another reason for the decrease in sexual harassment awareness has been the lack of attention it has been given by all the parties interviewed. The trade unions and the Human Resources professionals all admitted to having neglected sexual harassment over the years and acknowledged that it should be taken up again.

\section{The endogeneity model and sexual harassment policies and procedures}

The endogeneity model by Edelman \& Talesh (2011) focuses on how organisations interpret laws within their formal structures to endure compliance. They further explored the impact this compliance has on other organisational entities and finally how this compliance then infiltrates the legal logic through judicial rulings and legislation.

The research shows that all the organisations have sexual harassment sections in their policies and procedures or codes of conduct, but that they have remained largely unchanged since first implementation or even since the amendment of the Employment Relations Act in 2000. These findings are consistent with those of Edelman \& Talesh (2011) and McCann (2005) in term of organisations implementing formal policies and procedures so that they are able to show compliance with the law and thereby legitimacy to the organisation.

After compliance has been achieved the organisations add their own strategic goals and organisational values to the policies (Edelman, 1999), allowing the organisations a level of flexibility in the structures and preservation of managerial discretion (Gilad, 
2014). The research revealed that organisations themselves do not attach their values and goals to sexual harassment policies, the interviews showed that although the sexual harassment law has been adopted into the formal structure of policies and procedures within most organisations and trade unions, the wording of the policies is what is given in the legislation and has not been changed significantly.

Organisations translate the laws to best suit their organisational interests (Edelman, Fuller, \& Mara-Drita, 2001; Edelman, Uggen, \& Erlanger, 1999; Kagan et. al., 2003; Tyler, 1990). Although the research showed that there were no changes to the wording of the sexual harassment laws, there were changes to the length of the procedures section depending on the size of the organisation. The larger the organisation the more likely that the procedures to follow would be more complex than in a small organisation with fewer managers.

In line with the research by Edelman et al. (2001) and Edelman (2007) the data revealed that the organisations and professionals maintained a level of flexibility and managerial discretion in the complaints procedure for any alleged sexual harassment behaviour. The sexual harassment procedure details who the employee can approach for assistance if they feel that they have been sexually harassed. There is a similarity between all the procedures within the interviewed organisations with a two or three step process. It is recommended that the employee first approaches the harasser themselves, or has an informal meeting with a manager and the harasser or as a final measure lays an official grievance. The employees are further advised to keep record of repeated actions and to do this in writing.

The consultants confirmed that this procedure is the norm in New Zealand, and it is seen to be fair for the harassed employee as well as the accused employee and has become part of the legal environment. This aligns with the third step in the endogeneity model from Edelman and Talesh (2011) in that the compliance structures are imitated by other organisations.

There is no connection between the final step in the endogeneity model and sexual harassment legislation and policies in New Zealand. The model states that there is a blurring of organisational and legal fields which leads to an infiltration of the 
organisational values and procedures into the legal logic through judicial rulings and legislation. (Dobbin \& Kelly 2007; Edelman et al. 2011; Talesh 2009).

The research found no evidence of this and the sexual harassment cases which have been heard at the Employment Relations Authority (Newman $v$ Taxi Lease Ltd t/a The Plant Place 2014 [2014] NZERA; D v E Ltd August [2013] NZERA Auckland 338) also show no evidence of a significant change in the sexual harassment legislation before it is incorporated into organisational compliance structures. This movement from the organisation's compliance documents has not taken place and legal field logic has remained largely unchanged because of it. The endogeneity model assumes a dynamic interaction between parties in the organisational and legal fields, the research shows that this is not the case with sexual harassment legislation in New Zealand.

This suggests that the organisations are following a tick box approach to sexual harassment legislation compliance, where they are implementing sexual harassment policies which they do not necessarily understand and which contain the same wording as the legislation

\section{The strategic role of consultants and trade unions}

Third parties like trade unions and consultants play an important role in the compliance measures implemented by organisations, as well as the management of these measures. The third parties aid in the understanding of the legislation and ensure that the compliance measures like policies and procedures align with the legislation and are not misinterpreted. The third parties can have different interests when assisting organisations comply with legislation, particularly if the law is ambiguous and not clear and easy to understand. Trade unions interpret the laws in favour of their members and consultants could potentially align compliance to their personal professional goals in an attempt to maintain a demand for their services (Dobbin \& Kelly, 2007; Edelman, Uggen \& Erlanger, 1999).

\section{The role of Human Resources consultants}

Organisations use Human Resources consultants when they are not sure about the meaning of the law and as a way to ensure that they achieve correct compliance to the employment legislation. This is a rational way for organisations to avoid or limit 
legal action and negative press which may harm the organisation as a result of sexual harassment cases (Dobbin \& Kelly, 2007; Edelman, 1990).

The consultants explained that they are a source of advice for all sizes of organisations who either cannot afford to employ a Human Resources professional or who have Human Resources employees who are not comfortable with handling certain laws or situations. The main role played by the consultants is that of advisor and impartial external mediator when sexual harassment behaviour does occur in the workplace. Due to the sensitive nature of the complaints many organisations feel that it is better to have an external mediator to ensure that the case is handled professionally and correctly. It was revealed that larger organisations are making use of consultant's services at the investigation stage already, because they see it as best practice in the law and the most effective way to maintain independence from the reporting line and maintain relationships within the organisation.

The Human Resources consultants interviewed confirmed that regarding policies and procedures, organisations mainly consulted them when there was a need to draw up or review employment policies and procedures, but that this service was rarely requested specifically for sexual harassment policies as they are part of the policies as a whole.

In contrast to past research which found that third parties will align ambiguous laws to their professional goals and thereby maintaining a need for their services (Dobbin \& Kelly 2007; Edelman, Fuller \& Mara-Drita, 2001; Edelman et al., 1999), the study found that the Human Resources consultants feel that they offer a service to aid organisations in compliance particularly if the law is sensitive or difficult to understand. The maintained need for their services is usually due to the size of the organisation and smaller organisations will keep using consultants as it is more cost effective than a full-time Human Resources employee.

The study supports previous literature and reveals that Human Resources consultants certainly play a role in the endogeneity process by placing pressure on organisations to comply with sexual harassment legislation and implement appropriate policies and procedures. The consultants tend to give advice to several organisations spanning different industries. Therefore, through their mediation activities and compliance 
measures they institutionalise their compliance and best practice structures into several organisations where they are taken for granted as the norm within New Zealand. Within large organisations in the private and public sector the consultants play the role of compliance monitors, whereby they highlight any conflicting or contradictory issues within the compliance documents. This is again done with best practice in mind and as a way to avoid liability for the organisations should the policies and procedures be incorrect. This aligns with previous research by Edelman (1999).

The information from the consultants in this study does show that their influence on sexual harassment policies in organisations is limited to compliance and mediation and although they recommend ways to educate employees and distribute the information, their power is limited and they have no control over what happens to the documents after they finish the project.

\section{The role of trade unions}

Research in the impact of trade union activity in the implementation of sexual harassment policies and their effectiveness in decreasing this behaviour is severely limited not just in New Zealand but in all OECD countries. The findings of this study show why the trade unions have limited influence on sexual harassment policies in New Zealand.

In the 80's and 90's the trade unions were the driving force behind sexual harassment awareness and played a pivotal role in the implementation of the sexual harassment law into the employment relations legislation. Due to the significant loss in power over the last 26 years, and the lack of resources available to New Zealand trade unions, they are now seen mainly as advisers for their members and as information hubs about sexual harassment.

The trade unions do not actively hold management or organisations responsible for sexual harassment policies and procedures, they expect that organisations should have general employee policies but accept that many organisations in New Zealand do not have them.

The trade unions take a reactive stance when sexual harassment cases are brought to their attention and even then, are seen as source of advice by their members. 
Aligning with literature by Pierce and Aguinis (1997) the research shows that trade unions regularly have members experience sexual harassment in the workplace, but due to fear or job loss and even visa loss, they do not take the issue any further increasing the unknown numbers of sexual harassment cases in New Zealand.

Perhaps surprisingly, the unions confirmed that this reluctance to complain runs through all sectors and industries including the large public sector organisations which generally have complex and thorough policies and procedures on how to manage sexual harassment. In the past the trade unions had sexual harassment representatives with specialised knowledge about the sexual harassment law in the majority of large public sector organisations. These representatives acted as an impartial go-to person who would represent the employee directly in the workplace, although there are still union representatives in most public sector organisations, the training and information they have about sexual harassment is limited due to resource constraints thereby limiting their impact.

Human Resources departments further are not obliged to approach trade unions for advice when drawing up or managing any of their employment policies and the trade unions are only actively involved in collective bargaining agreements for their members. This lack of interaction with the Human Resources departments may be an attempt by the organisations and the Human Resources professionals to maintain their managerial integrity and flexibility within the organisation as well as Human Resources authority (Edelman, 1999; Gilad, 2014).

\section{Training and information}

The study revealed that training is seen as a practicable step for organisations to take to increase awareness and decrease the occurrence of sexual harassment behaviour in the workplace. Particular emphasis was placed on training of managers and senior staff to help them deal with sexual harassment complaints should they arise. This confirms previous literature by Choi et al. (2009) in which it was found that training programmes increase employee satisfaction and reduce turn-over and Calvasina (2005) who found that increased response rates by qualified employees reduces sexual harassment in the workplace. 
None of the participants had taken part or sent their senior staff on any specifically sexual harassment training for several years even though they admitted it needed to be done. There had been training given for general harassment and bullying but due to a lack of demand sexual harassment training was not given and there were no plans for it into the future.

Further in line with past research by Pratten and Lovatt (2005), the size of the organisations determines whether they will have qualified employee to manage sexual harassment cases. The study revealed that smaller organisations have no sexual harassment information or policies and do not take part in any training. When a sexual harassment complaint does arise in small organisations, they tend to respond with panic due to inadequate knowledge on how to deal with the situation.

\section{Recommendations}

This research presents several practical recommendations for the understanding and effective use of sexual harassment legislations and policies.

Firstly, the research suggests that sexual harassment has been largely ignored and marginalised due to a perceived decrease in complaints within organisations and at the various authorities. As the study reveals, it is not necessarily the case that actual sexual harassment has declined and there are unknown numbers of sexual harassment cases just not being reported. There is a need to revive sexual harassment awareness within organisations so that employees become aware of which actions are classified as sexual harassment and what their rights are. This means that there should be a zero-tolerance approach to sexual harassment in organisations, and that the sexual harassment policies need to be turned into living documents which are transparent and easy to use for the employees, making it easier for them to report any incidents.

Secondly, although the sexual harassment legislation is meant to be easy to understand for organisations and employees, the ambiguity of certain words and the rulings from cases, has made it almost impossible to understand which actions are seen as sexual in nature for the average person. This may be another reason why employees are reluctant to report sexual harassment incidents. The legislators need to consider clarifying the meaning of the ambiguous words with a detailed guideline 
for the organisations as well as the employees. Included in the guideline should be actions which are not considered to be sexual harassment as well as those that are. As the case law around sexual harassment evolves, it is possible that these guidelines will change and there will be a need for regular reviews.

Thirdly, the trade unions are seen primarily as advisers and mediators in sexual harassment issues. This research has highlighted that trade unions are generally seen positively despite the loss of power over the last years. Considering the impact the trade unions had in the women's rights movement in the 80's and 90's, they play an important role in awareness of sexual harassment and should pay as much attention to sexual harassment as they currently do to bullying, using the same information channels like booklets and conferences.

Fourthly, the research highlighted that the current resolution systems for sexual harassment are not adequate to stop the behaviour. The financial repercussions for organisations and harassers are not enough to motivate them to implement zerotolerance policies on sexual harassment in their workplaces. A substantial increase in the fines and awards should sexual harassment occur could result in a decrease of sexual harassment in the workplace.

\section{Chapter 6: Conclusion, limitations and future research}

\section{Conclusion}

The sexual harassment law is understood by organisations to a basic level and the ambiguity of certain wording has made it difficult for even the professionals to understand exactly when sexual harassment has taken place.

The employment legislation does not specify how sexual harassment should be incorporated into organisational policies and procedures and this is resulting in tick box compliance. This tick box compliance may ensure that the organisations are complying with the written part of the law, but they are failing to monitor if the policies and procedures they have put into place are effective or are being used by the employees.

The legal consciousness of sexual harassment has decreased due to a lack of attention and the organisations are taking them for granted, there is an assumption 
that the policies are there and it is the employee's responsibility to use them if they are needed.

The research has further revealed that the organisations are not prioritising sexual harassment within the organisations and the policies have been neglected in favour of bullying policies which is seen as a greater problem in New Zealand by all participants.

The lack of attention to the sexual harassment policies and the inadequate data about how many cases of sexual harassment are happening, means that the flow of the law has stalled, nothing is changing because nothing is happening and the organisations have become reactive to sexual harassment. This reactive approach has resulted in a decreased legal consciousness within the organisations.

The dynamic movement of the law which is described in the endogeneity model (Edelman \& Talesh, 2011), does not apply to the sexual harassment law in New Zealand. The movement has stopped at the compliance stage and the organisations are implementing policies which comply to the norm and are then given little attention. The flow from the organisations to the legal environment is limited due to a small number of sexual harassment claims going past the mediation phase and actually being heard, this has led to the law remaining unchanged.

This study has highlighted that third parties like Human Resources consultants and trade unions, do still play an important role in the formation and implementation of sexual harassment policies, but it became apparent that they mostly act as advisers and mediators, and do not have an impact on changing the tick box culture.

There is a need to rework the legislation and make it more user friendly for the organisations and employees using a similar guideline to the bullying handbook from WorkSafe. Organisations and trade unions have allowed sexual harassment awareness to fall by the wayside which could have severe consequences for the employees as well as the organisations themselves, as is seen by the sudden influx of claims due to the increased awareness caused by the "Weinstein effect" in America.

\section{Limitations and future research}

The research looked at the relationship between the sexual harassment legislations and how it is understood by organisations and consequently implemented in order to 
reach compliance. Several limitations in the research are acknowledged and these provide the basis for potential future research.

Firstly, this study looked at the relationship between the legislation and organisational policies using the interview data from 11 participants. The 4 trade unions interviewed as well as the 3 Human Resources consultants are active throughout New Zealand, but the 4 organisations interviewed are all based in Wellington. Future studies should explore organisations in other cities in New Zealand and possibly other OECD countries, and apply the findings in this research to other contexts.

Secondly, in this study this loss of legal consciousness is focused on the parties who are directly involved with the law and the policies, it does not take into consideration the legal consciousness of the employees. This could be an area for future research to discover if the loss of the understanding and awareness of the sexual harassment legislation and policies has filtered down to the employees too.

Thirdly, the study explored what the organisations, consultants and trade unions understand as sexual harassment behaviour, but it did not research what the employees themselves perceive as sexual harassment and what recourse they think they have within the organisation. Additional research into this would result in a full picture of sexual harassment knowledge within organisations as well as an understanding of whether the policies are effective in promoting reporting.

Fourth, the new increase in sexual harassment cases against prominent men around the world has sparked a social media awareness campaign where women and men have been encouraged to share their experiences with other users. This was not explored in this research due to its timing, future studies could explore if there is an increase in sexual harassment complaints as a result of this increases awareness due to social media and if consequently there is a change in the judicial rulings and then the legislation. 


\section{References}

Aikenhead, G. (1997, May). A framework for reflecting on assessment and evaluation. In Globalization of Science Education: International Conference on Science Education, Seoul, Korea (pp. 26-30).

Ambiguity (Def.1). (n.d.). Duhaime's Law Dictionary. Retrieved October 19, 2017, from: http://www.duhaime.org/LegalDictionary/A/Ambiguity.aspx

Baker, D. D., Terpstra, D. E., \& Larntz, K. (1990). The influence of individual characteristics and severity of harassing behavior on reactions to sexual harassment. Sex Roles, 22(5-6), 305-325.

https://doi.org/10.1007/BF00288336

Bell, M. P., Quick, J. C., \& Cycyota, C. S. (2002). Assessment and prevention of sexual harassment of employees: An applied guide to creating healthy organizations. International Journal of Selection and Assessment, 10(1-2), 160-167. https://doi.org/10.1111/1468-2389.00203

Bergman, M. E., Langhout, R. D., Palmieri, P. A., Cortina, L. M., \& Fitzgerald, L. F. (2002). The (un)reasonableness of reporting: Antecedents and consequences of reporting sexual harassment. The Journal of Applied Psychology, 87(2), 230-242. https://doi.org/10.1037/0021-9010.87.2.230

Blackstone, A., Uggen, C., \& McLaughlin, H. (2009). Legal consciousness and responses to sexual harassment. Law \& Society Review, 43(3), 631-668. https://doi.org/10.1111/j.1540-5893.2009.00384.x

Blumenfeld, S. 2015. New Zealand's employment law agenda 2014: Collective bargaining and unions in an election year. New Zealand Journal of Employment Relations (Online), 40(1), 70.

Boyatzis, R. E. (1998). Transforming qualitative information: Thematic analysis and code development. Sage (Atlanta, Ga.).

Brough, P., \& Frame, R. (2004). Predicting police job satisfaction and turnover intentions: The role of social support and police organisational variables. New Zealand Journal of Psychology,33(1), 8-18. 
Brownmiller, S. (1975). Against our will: Men, women and rape. Harmondsworth: Penguin Books.

Bumsted, A., \& Boyce, T. E. (2005). Exploring the effects of cultural variables in the implementation of behavior-based safety in two organizations. Journal of Organizational Behavior Management, 24(4), 43-63. https://doi.org/10.1300/J075v24n04_03

Cairns, K. (1997). 'Femininity' and women's silence in response to sexual harassment and coercion in McDonald, P. (2012). Workplace sexual harassment 30 years on: A review of the literature. International Journal of Management Reviews, 14(1), 1-17.

Calvasina, G. E. (2005). Responding to allegations of 3rd party sexual harassment: The customer is not always right. Journal of Legal, Ethical, and Regulatory Issues, 8(2), 71-81.

Chamberlain, L. J., Crowley, M., Tope, D., \& Hodson, R. (2008). Sexual harassment in organizational context. Work and Occupations, 35(3), 262-295. https://doi.org/10.1177/0730888408322008

Chan, S. M. (2013). Negotiating Gender and Police Culture: Exploring the Barriers to Retention and Progression of Female Police Officers in New Zealand.

Choi, Y., \& Dickson, D. R. (2009). A case study into the benefits of management training programs: Impacts on hotel employee turnover and satisfaction level. Journal of Human Resources in Hospitality \& Tourism, 9(1), 103-116. https://doi.org/10.1080/15332840903336499

Clark, M. (2006). Entering the business of behavior change: Motivational interviewing for probation staff. Perspectives - American Probation and Parole Association, 30(1), 38-45.

Clayton, S. D. (1992). Remedies for discrimination: Race, sex and affirmative action. Behavioral Sciences \& the Law, 10(2), 245-257. https://doi.org/10.1002/bsl.2370100208 
Collins v Smith [2015] VCAT 1992; 256 IR 52. Retrieved from:

https://www.humanrightscommission.vic.gov.au/home/submissions/legalsubmissions/item/1352-collins-v-smith

Collinson, M., \& Collinson, D. (1996). It's only Dick': The sexual harassment of women managers in insurance sales. Work, Employment and Society, 10(1), 29-56. https://doi.org/10.1177/0950017096101002

Connell, R. W. (1987). Gender and power Cambridge. Polity, $\cdots$, , 279-304.

Cortina, L. M., Lonsway, K. A., Magley, V. J., Freeman, L. V., Collinsworth, L. L., Hunter, M., \& Fitzgerald, L. F. (2002). What's gender got to do with it? Incivility in the federal courts. Law \& Social Inquiry, 27(2), 235-270. https://doi.org/10.1111/j.1747-4469.2002.tb00804.x

Cowan, D. (2004). Legal consciousness: Some observations. The Modern Law Review, 67(6), 928-958. https://doi.org/10.1111/j.1468-2230.2004.00518.x

Creswell, J. (1998). W. (1998). Qualitative inquiry and research design: Choosing among five traditions, 2.

D v E Ltd August [2013] NZERA Auckland 338. Retrieved from:

http://apps.employment.govt.nz/determinations/FullSummary.aspx?ID=76420 097

Denison, D. R. (1996). What is the difference between organizational culture and organizational climate? A native's point of view on a decade of paradigm wars. Academy of Management Review, 21(3), 619-654.

DeSouza, E. R., Solberg, J., \& Elder, C. (2007). A cross-cultural perspective on judgments of woman-to-woman sexual harassment: Does sexual orientation matter? Sex Roles, 56(7-8), 457-471. https://doi.org/10.1007/s11199-0079184-6

DML v Montgomery [2014] NZHRRT 6. Retrieved from: https://www.justice.govt.nz/assets/Documents/Decisions/2014-NZHRRT-6DML-v-Montgomery-and-MT-Enterprises-Ltd.pdf 
Dobbin, F., \& Kelly, E. L. (2007). How to stop harassment: Professional construction of legal compliance in organizations. American Journal of Sociology, 112(4), 1203-1243. https://doi.org/10.1086/508788

Eaton, D. (2004). Beyond room service: Legal consequences of sexual harassment of staff by hotel guests. The Cornell Hotel and Restaurant Administration Quarterly, 45(4), 347-361. https://doi.org/10.1177/0010880404270064

Edelman, L. B. (1990). Legal environments and organizational governance: The expansion of due process in the American workplace. American Journal of Sociology, 95(6), 1401-1440. https://doi.org/10.1086/229459

Edelman, L. B. (2004). The Legal Lives of Private Organizations. The Blackwell Companion to Law and Society, 231-252.

Edelman, L. B., Abraham, S. E., \& Erlanger, H. S. (1992). Professional construction of law: The inflated threat of wrongful discharge. Law \& Society Review, 26(1), 47-83. https://doi.org/10.2307/3053836

Edelman, L. B., Fuller, S. R., \& Mara-Drita, I. (2001). Diversity rhetoric and the managerialization of law. American Journal of Sociology, 106(6), 15891641. https://doi.org/10.1086/321303

Edelman, L. B., \& Talesh, S. A. (2011). To comply or not to comply-That isn't the question: How organizations construct the meaning of compliance. Explaining compliance: Business responses to regulation, 103-122.

Edelman, L. B., Uggen, C., \& Erlanger, H. S. (1999). The endogeneity of legal regulation: Grievance procedures as rational myth. American Journal of Sociology, 105(2), 406-454. https://doi.org/10.1086/210316

Employment Relations Act 2000 Retrieved from:

http://www.legislation.govt.nz/act/public/2000/0024/latest/DLM58317.html

Ewick, P., \& Silbey, S. S. (1998). The common place of law: Stories from everyday life. University of Chicago Press. 
Eyre, L. 2000. The discursive framing of sexual harassment in a university community. Gender and Education, 12(3), 293-307. https://doi.org/10.1080/713668301

Faugier, J., \& Sargeant, M. (1997). Sampling hard to reach populations. Journal of Advanced Nursing, 26(4), 790-797. https://doi.org/10.1046/j.13652648.1997.00371.x

Felstiner, W. L., Abel, R. L., \& Sarat, A. (1980). The Emergence and Transformation of Disputes: Naming, Blaming, Claiming.... Law \& Society Review, 15(3/4), 631-654. https://doi.org/10.2307/3053505

Fitzgerald, L. F., Swan, S., \& Fischer, K. (1995). Why didn't she just report him? The psychological and legal implications of women's responses to sexual harassment. The Journal of Social Issues, 51(1), 117-138. https://doi.org/10.1111/j.1540-4560.1995.tb01312.x

Folgerø, I. S., \& Fjeldstad, I. H. (1995). On duty—off guard: Cultural norms and sexual harassment in service organizations. Organization Studies, 16(2), 299313. https://doi.org/10.1177/017084069501600205

Gratton, C., \& Jones, I. (2004). Analyzing data II: Qualitative data analysis. Research methods for sport studies, 217-227.

Gray, D. E. (2013). Doing research in the real world. Sage (Atlanta, Ga.).

Gilad, S. (2014). Beyond Endogeneity: How Firms and Regulators Co-Construct the Meaning of Regulation. Law \& Policy, 36(2), 134-164. https://doi.org/10.1111/lapo.12017

Gough, S., \& Scott, W. 2000. Exploring the purposes of qualitative data coding in educational enquiry: Insights from recent research. Educational Studies, 26(3), 339-354. https://doi.org/10.1080/03055690050137141

Gruber, J. E. (1998). The impact of male work environments and organizational policies on women's experiences of sexual harassment. Gender \& Society, 12(3), 301-320. https://doi.org/10.1177/0891243298012003004 
Gruber, J. E., \& Smith, M. D. (1995). Women's responses to sexual harassment: A multivariate analysis. Basic and Applied Social Psychology, 17(4), 543562. https://doi.org/10.1207/s15324834basp1704_7

Gunningham, N., Kagan, R. A., \& Thornton, D. (2004). Social license and environmental protection: Why businesses go beyond compliance. Law \& Social Inquiry, 29(2), 307-341. https://doi.org/10.1111/j.17474469.2004.tb00338.x

Gutek, B. A., \& Koss, M. P. 1993. Changed women and changed organizations: Consequences of and coping with sexual harassment. Journal of Vocational Behavior, 42(1), 28-48. https://doi.org/10.1006/jvbe.1993.1003

Handy, J. (2006). Sexual Harassment in Small-Town New Zealand: A Qualitative Study of Three Contrasting Organizations. Gender, Work and Organization, 13(1), 1-24. https://doi.org/10.1111/j.1468-0432.2006.00293.x Health and Safety at Work Act 2015 Retrieved from: http://www.legislation.govt.nz/act/public/2015/0070/latest/DLM5976660.html

Heckathorn, D. D. (2002). Respondent-driven sampling II: Deriving valid population estimates from chain-referral samples of hidden populations. Social Problems, 49(1), 11-34. https://doi.org/10.1525/sp.2002.49.1.11

Hegewisch, A., Deitch, C. H., \& Murphy, E. F. (2011). Ending sex and race discrimination in the workplace: Legal interventions that push the envelope. Institute for Women's Policy Research.

Hertzog, J. L., Wright, D., \& Beat, D. (2008). There's a policy for that: A comparison of the organizational culture of workplaces reporting incidents of sexual harassment. Behavior and Social Issues, 17(2), 169. https://doi.org/10.5210/bsi.v17i2.2175

Hill, L. (1994). Feminism and unionism in New Zealand. Hecate, 20(2), 124. https://search.proquest.com/docview/210904281?pq-origsite=gscholar Huberman, M., \& Miles, M. B. (2002). The qualitative researcher's companion. Sage (Atlanta, Ga.). 
Human Rights Act 1993 Retrieved from:

http://www.legislation.govt.nz/act/public/1993/0082/latest/DLM304212.html

Husbands, R. (1992). Sexual harassment law in employment: An international perspective. Int'l Lab. Rev., 131, 535.

Hyman, P. 2000. Opportunities for and Barriers to the Recruitment, Progress, and Retention of Women in the Criminal Investigation Branch (CIB). New Zealand Police.

International labour Organisation (2017). Violence and harassment against women and men in the world of work: trade union perspectives and action. International Labour Office, Bureau for Workers' Activities (ACTRAV). - Geneva. Retrieved from: http://www.ilo.org/wcmsp5/groups/public/---ed_dialogue/--actrav/documents/publication/wcms_546645.pdf

Jones, S. S., Boocock, K., \& Underhill-Sem, Y. (2013). '[PDF] Being harassed? 'Accessing information about sexual harassment in New Zealand's universities. Women's Studies Journal,27(1), 36. http://wsanz.org.nz/journal/docs/WSJNZ271JonesBoocockUnderhill-Sem3648.pdf

Kaplan, B., \& Maxwell, J. A. (1994). Evaluating health care information systems: Methods and applications. Qualitative Research Methods for Evaluating Computer Information Systems. JG Anderson, CE Ayden and SJ Jay. Thousand Oaks: Sage.

Knapp, D. E., Faley, R. H., Ekeberg, S. E., \& Dubois, C. L. (1997). Determinants of target responses to sexual harassment: A conceptual framework. Academy of Management Review,22(3), 687-729. https://journals.aom.org/doi/abs/10.5465/amr.1997.9708210723

Krawiec, K. D. (2003). Cosmetic compliance and the failure of negotiated governance. Wash. ULQ, 81, 487. https://openscholarship.wustl.edu/cgi/viewcontent.cgi?referer=https://www.goog le.co.nz/\&httpsredir=1\&article=1288\&context=law_lawreview 
Kumar v Icehouse (NZ) Ltd [2006] ERNZ 381 (EmpC); L v M Ltd [1994] 1 ERNZ 123 (ET). Retrieved

from: https://employmentcourt.govt.nz/assets/Documents/Decisions/ARC-3905-CHANDRA-KUMAR-V-ICEHOUSE-NZ-LTD-JUDG-JTK-9.pdf

Kwortnik, R. J. (2003). Clarifying "fuzzy" hospitality-management problems with depth interviews and qualitative analysis. The Cornell Hotel and Restaurant Administration Quarterly,44(2), 117-129. https://doi.org/10.1016/S00108804(03)90025-5

Lee, D. 2000. Hegemonic masculinity and male feminisation: The sexual harassment of men at work. Journal of Gender Studies, 9(2), 141155. https://doi.org/10.1080/713677986

Lester, S. (1999). An introduction to phenomenological research. Taunton UK, Stan Lester Developments.

https://www.researchgate.net/profile/Stan_Lester/publication/255647619_An_in troduction_to_phenomenological_research/links/545a05e30cf2cf5164840df6.p df

Lim, S., \& Cortina, L. M. (2005). Interpersonal mistreatment in the workplace: The interface and impact of general incivility and sexual harassment. The Journal of Applied Psychology, 90(3), 483-496. https://doi.org/10.1037/00219010.90 .3 .483

Littlejohn, S. W., \& Foss, K. A. (2009). Encyclopedia of Communication Theory (Vol. 1). SAGE Publication. https://doi.org/10.4135/9781412959384

MacGregor v Craig [2016] NZHRRT 6. Retrieved from: https://www.justice.govt.nz/assets/Documents/Decisions/v2-2016NZHRRT-6-MacGregor-v-Craig.pdf

MacKinnon, C. A. (1979). Sexual harassment of working women: A case of sex discrimination (No. 19). Yale University Press.

Marshall, A. M., \& Barclay, S. (2003). In their own words: How ordinary people construct the legal world. Law \& Social Inquiry, 28(3), 617-628. https://doi.org/10.1111/j.1747-4469.2003.tb00209.x 
Mason, M. (2010, August). Sample size and saturation in PhD studies using qualitative interviews. In Forum qualitative Sozialforschung/Forum: qualitative social research (Vol. 11, No. 3).

McCann, D. (2005). Sexual harassment at work: national and international responses (No. 2). International Labour Organization. http://dro.dur.ac.uk/15039/1/15039.pdf

McDonald, P. (2012). Workplace sexual harassment 30 years on: A review of the literature. International Journal of Management Reviews, 14(1), 1-17. https://doi.org/10.1111/j.1468-2370.2011.00300.x

McDonald, P., \& Charlesworth, S. (2013). Framing sexual harassment through media representations. [). Pergamon.]. Women's Studies International Forum, 37, 95-103. https://doi.org/10.1016/j.wsif.2012.11.003

McLaughlin, H., Uggen, C., \& Blackstone, A. (2012). Sexual harassment, workplace authority, and the paradox of power. American Sociological Review, 77(4), 625-647. https://doi.org/10.1177/0003122412451728

McNamara, C. (1999). General guidelines for conducting interviews. Minnesota. Missouri Institute of science.

Merry, S. E. (1990). Getting justice and getting even: Legal consciousness among working-class Americans. University of Chicago Press.

Monette, D. R., Sullivan, T. J., \& DeJong, C. R. (2010). Applied social research: Tool for the human services. Belmont, CA: Brooks/Cole.

Montgomery, K., Kane, K., \& Vance, C. M. (2004). Accounting for differences in norms of respect: A study of assessments of incivility through the lenses of race and gender. Group \& Organization Management, 29(2), 248-268. https://doi.org/10.1177/1059601103252105

Mueller, C. W., De Coster, S., \& Estes, S. B. (2001). Sexual harassment in the workplace: Unanticipated consequences of modern social control in organizations. Work and Occupations, 28(4), 411-446. https://doi.org/10.1177/0730888401028004003 
Myers, M. D. (2008). Qualitative Research in Business \& Management. SAGE Publications.

Newman v Taxi Lease Ltd t/a The Plant Place November [2014] NZERA Auckland 481. Retrieved from:

http://apps.employment.govt.nz/determinations/FullSummary.aspx?ID=764214 62

New Zealand Human Rights Commission (2001). Human Rights Annual Report. Human Rights Commission, Auckland: New Zealand Retrieved from: http://www.rwi.lu.se/NHRIDB/Asia/New\%20Zeeland/Annual\%20report\%2 001.pdf

New Zealand Human Rights Commission. (2012). Census of Women's participation 2012 of the New Zealand Human Rights Commission. Retrieved from: https://www.hrc.co.nz/your-rights/business-and-work/tools-andresearch/census-womens-participation/

New Zealand Human Rights Commission (2001). Unwelcome and Offensive. Human Rights Commission, Auckland: New Zealand. Retrieved from: http://www.rwi.lu.se/NHRIDB/Asia/New\%20Zeeland/Annual\%20report\%2001.p df

Neill, J. (2006) Paradigms. Retrieved from: http://wilderdom.com/OEcourses/PROFLIT/Class6Qualitative1.htm

Nielsen, L. B. 2000. Situating legal consciousness: Experiences and attitudes of ordinary citizens about law and street harassment. Law \& Society Review, 34(4), 1055-1090. https://doi.org/10.2307/3115131

O'Hare, E. A., \& O'Donohue, W. (1998). Sexual harassment: Identifying risk factors. Archives of Sexual Behavior, 27(6), 561-580. https://doi.org/10.1023/A:1018769016832

O'Leary, Z. (2005). Researching real-world problems: A guide to methods of inquiry. Sage (Atlanta, Ga.). 
Owen v The Chief Executive of the Department of Corrections July [2016] NZERA Auckland 253. Retrieved from:

http://apps.employment.govt.nz/determinations/FullSummary.aspx?ID=764228 35

Oxenbridge, S. (1997). Organizing strategies and organizing reform in New Zealand service sector unions. Labor Studies Journal, 22, 3.

Poulston, J. (2008). Metamorphosis in hospitality: A tradition of sexual harassment. International Journal of Hospitality Management, 27(2), 232240. https://doi.org/10.1016/j.ijhm.2007.07.013

Pratten, J. D., \& Lovatt, C. J. (2005). The impact of employment legislation on micro businesses: A case study from the licensed trade. Journal of Small Business and Enterprise Development,12(2), 290300. https://doi.org/10.1108/14626000510594665

Pierce, C. A., \& Aguinis, H. (1997). Bridging the gap between romantic relationships and sexual harassment in organizations. Journal of Organizational Behavior, 18(3), 197-200. https://doi.org/10.1002/(SICI)10991379(199705)18:3<197::AID-JOB812>3.0.CO;2-O

Popovich, P. M., \& Warren, M. A. (2010). The role of power in sexual harassment as a counterproductive behavior in organizations. Human Resource Management Review, 20(1), 45-53.

https://www.sciencedirect.com/science/article/pii/S1053482209000497

Proceedings Commissioner v Sahay and Anor August [1996] CRT 9/95 (Decision 34/96)

Quinn, B. A. 2000. The paradox of complaining: Law, humor, and harassment in the everyday work world. Law \& Social Inquiry, 25(4), 1151-1185. https://doi.org/10.1111/j.1747-4469.2000.tb00319.x

Reese, L. A., \& Lindenberg, K. E. (2004). Employee satisfaction with sexual harassment policies: The training connection. Public Personnel Management, 33(1), 99-119. https://doi.org/10.1177/009102600403300108 
Richardson v Oracle Corporation Australia Pty Ltd [2014] FCAFC 82. Retrieved from: http://ww3.lawschool.cornell.edu/AvonResources/Richardson\%20v\%200racle \%20Corporation\%20Australia\%20Pty\%20Ltd\%20[2014]\%20FCAFC\%2082.pdf

Robinson, K. H. (2005). Reinforcing hegemonic masculinities through sexual harassment: Issues of identity, power and popularity in secondary schools. Gender and Education, 17(1), 19-37. https://doi.org/10.1080/0954025042000301285

Rudman, R. (2016). New Zealand Employment Law Guide (2016 edition). CCH New Zealand Limited.

Silbey, Susan (2008). "legal consciousness" (PDF). New Oxford Companion to Law: 2. http://web.mit.edu/ssilbey/www/pdf/Legal_consciousness.pdf

Singh v Palaniammah Ltd and Ors 31 August [2015] NZERA Wellington 84 Retrieved from: http://apps.employment.govt.nz/determinations/FullSummary.aspx?ID=764226 52

Statistics South Africa. (2016). Labour market dynamics in South Africa, 2015. Pretoria: South Africa, 2016. Retrieved from: https://www.statssa.gov.za/publications/Report-02-11-02/Report-02-11022015.pdf

Sutton, J. R., Dobbin, F., Meyer, J. W., \& Scott, W. R. (1994). The legalization of the workplace. American Journal of Sociology, 99(4), 944-971. https://doi.org/10.1086/230368

Timmerman, G., \& Bajema, C. 2000. The impact of organizational culture on perceptions and experiences of sexual harassment. Journal of Vocational Behavior, 57(2), 188-205. https://doi.org/10.1006/jvbe.1999.1741

Trochim, W., \& Donnelly, J. (2006). The research knowledge methods base. Cincinnati, $\mathrm{OH}$ : Atomic Dog Publishing.

Vogt, W. P. (1999). Dictionary of Statistics and Methodology: A Nontechnical Guide for the Social Sciences. London: Sage. 
Waldo, C. R., Berdahl, J. L., \& Fitzgerald, L. F. (1998). Are men sexually harassed? If so, by whom? Law and Human Behavior, 22(1), 59-79. https://doi.org/10.1023/A:1025776705629

Waudby, B. H. (2012). Employee experiences and perceptions of sexual harassment in hospitality: an exploratory study (Doctoral dissertation, Auckland University of Technology).

http://aut.researchgateway.ac.nz/bitstream/handle/10292/5522/WaudbyBH.pdf? sequence $=5 \&$ isAllowed $=y$

Wear, D., Aultman, J. M., \& Borges, N. J. (2007). Retheorizing sexual harassment in medical education: Women students' perceptions at five U.S. medical schools. Teaching and Learning in Medicine, 19(1), 20-29.

https://doi.org/10.1080/10401330709336619

Welsh, S. (1999). Gender and sexual harassment. Annual Review of Sociology, 25(1), 169-190. https://doi.org/10.1146/annurev.soc.25.1.169

WorkSafe NZ. (2014). Preventing and responding to workplace bullying: Best practice guidelines. Wellington: WorkSafe NZ Retrieved from:

https://www.worksafe.govt.nz/worksafe/information-guidance/all-guidanceitems/bullying-guidelines/workplace-bullying

World Policy Analysis Center (2017). Preventing gender-based workplace discrimination and sexual harassment: New data on 193 countries. Retrieved from:

https://www.worldpolicycenter.org/sites/default/files/WORLD\%20Discrimination \%20at\%20Work\%20Report.pdf

Williams, C. (2003). Sexual harassment and human rights law in New Zealand. Journal of Human Rights, 2(4), 573-584. https://doi.org/10.1080/1475483032000137147

Yagil, D. (2008). When the customer is wrong: A review of research on aggression and sexual harassment in service encounters. Aggression and Violent Behavior, 13(2), 141-152. https://doi.org/10.1016/j.avb.2008.03.002 


\title{
Appendices
}

\section{Appendix A}

\section{Participant information sheet: organisations}

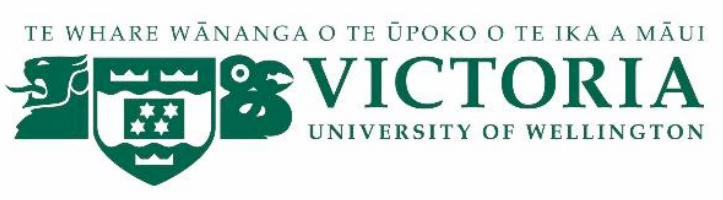

\begin{abstract}
A study of the interplay between law and organisational codes of conduct with regards to sexual harassment in the workplace in New Zealand.
\end{abstract}

\section{ABOUT THE RESEARCH: ORGANISATIONS}

My name is Heike Menne-Spohr and I am studying for my MCOM in HR/IR at Victoria University in Wellington. During my studies the topic of sexual harassment in the workplace drew my attention after I wrote an assignment focusing on the legal framework of sexual harassment in the workplace in New Zealand. The result showed that there seems to be some inconsistencies in interpretation in the law in cases in the Employment Relations Authority and the Human Review Tribunal. Coming from a Human Resources background, I began to wonder how these legal frameworks are interpreted within the context of the organisations who are expected to do this accurately.

This research project therefore aims to study how organisations construct the meaning of compliance with the law and how the legal employment frameworks surrounding sexual harassment are implemented within the workplace through policies, procedures and initiatives. I am further looking to see how trade unions have an effect on the implementation of policies and procedures within the organisations and if this participation has aided in the effectiveness of sexual harassment policies in the workplace. 
In this phase of the research I am asking a range of people with expertise in the implementation and interpretation of sexual harassment policies within organisations in New Zealand to help me develop a big picture of the possible challenges faced by legislators, organisations and trade unions when developing and implementing sexual harassment policies and procedures. The project is based at the Victoria University of Wellington, and is being conducted as part of a Master's degree in HR/IR.

I plan to conduct a series of interviews with HR professionals within organisations in New Zealand who have an overall perspective of sexual harassment policies within their organisations. The organisations may be public and private sector, as well as non-profit organisations. I will also be interviewing policy makers and representatives within trade unions in New Zealand. These interviews will be semi-structured and will last about one hour. I will ask questions about your ideas, experiences and opinions on the implementation of sexual harassment policies and procedures within the organisation.

The interview will be recorded. The recordings and transcripts will be kept confidential to the researcher and the supervisor of this project. The names of any interviewees will not be used nor will the names of their organisations. I will not use any quotations in such a way that participants or their organisation can be publicly identified. You will be provided with their transcript of the interview (if requested) and can give comments and feedback if you wish within 2 weeks of receipt. Participants can withdraw from the research project at any stage before data analysis [January 2017], without having to give a reason.

All information will be kept securely for a period of up to five years after the project [January 2023], and will then be destroyed.

After the interviews are analysed the findings may be used for academic publications, conference presentations, and public reports. The findings of these interviews will be used for a Master's thesis that is publicly available. If requested, participants will be offered a feedback summary report and a presentation on the results of the research when it has been completed. 


\section{What does this mean for you?}

- I am asking you to participate in a one-hour interview

- I will be asking you about the policies and procedures which are in place within your organisation specifically related to sexual harassment

- You will sign a consent form

Please do not hesitate to contact the researcher or supervisor if you have any questions.

Approval for the research has been granted by the Victoria University of Wellington Human Ethics Committee with approval number 0000023643.

For queries regarding the Human Ethic approval please contact:

Chair of the HEC: Associate Professor Susan Corbett

Victoria University Wellington, 044635480

susan.corbett@vuw.ac.nz

Researcher contact information

Supervisor contact information 


\section{Appendix B}

Interview questions for organisations

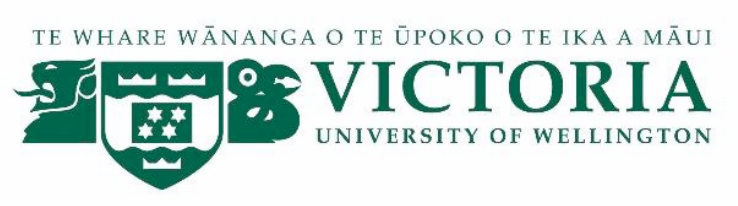

$\underline{\text { Interview questions (Organisations) }}$

This interview schedule outlines a list of likely questions which will be asked of participants. The format of all interviews will be semi-structured; however, this schedule will be used as a guide. The exact form of any questions to be asked in any given interview may change, depending on the focus of the interview and the information obtained during the interview. Some questions may not be asked or answered if there is a breach with any current issues regarding sexual harassment in the workplace.

List of questions:

1. Can you please start by telling me what your current role is within the organisation?

2. Please briefly describe the organisation you work for.

3. Does the organisation have an approach for dealing and/or preventing sexual harassment in the workplace?

4. Is any information about sexual harassment readily available in the workplace?

5. In the unlikely event of incidents of sexual harassment, does the organisation have any initiatives in place to prevent or to handle cases of sexual harassment in the workplace?

6. What was the process used within the organisation to devise these initiatives?

7. Has the organisation had the opportunity to review these initiatives to see the effectiveness and how were these initiatives measured? 
8. Has the organisation put any review processes in place for its sexual harassment policies and procedures? If so, how often do these policies and procedures get reviewed?

9. Does the organisation have a trade union present?

10. If yes to 9 , have they played a role in the implementation of the sexual harassment policies and procedures?

11. If no to 9 , is there a reason why the trade union didn't play a role in the implementation of sexual harassment policies and procedures?

12. What are the key challenges facing your organisation with regards to sexual harassment in the workplace?

13. Do you feel that the current sexual harassment legislation is clear and easily understandable?

14. Are there any current developments regarding sexual harassment which the organisation is working on? 


\section{Appendix C}

\section{Interview questions for trade unions}

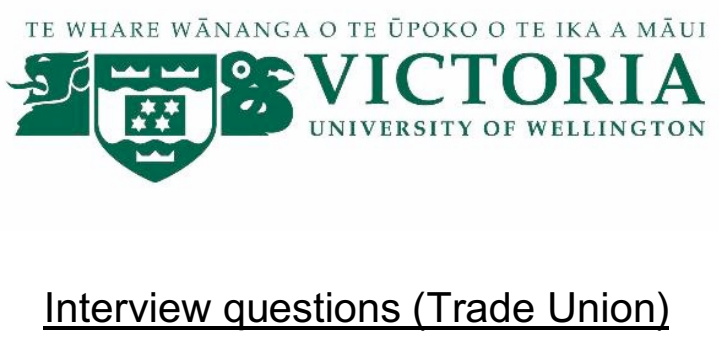

This interview schedule outlines a list of likely questions which will be asked of participants. The format of all interviews will be semi-structured, however this schedule will be used as a guide. The exact form of any questions to be asked in any given interview may change, depending on the focus of the interview and the information obtained during the interview.

\section{List of questions:}

1. Can you please start by telling me what your current role is within the trade union?

2. Please briefly describe the role of your trade union and which industry it focuses on.

3. What does the trade union define as sexual harassment in the workplace?

4. Does the union offer any information about sexual harassment in the workplace to your members?

5. What is the trade union's approach to dealing with sexual harassment incidents in the workplace?

6. Do the union representatives within the organisations have clear guidelines on how to handle sexual harassment incidents?

7. Does the trade union have any initiatives in place to help handle incidents of sexual harassment in the workplace and are getting sufficient support from the organisations? 
8. Are these initiatives effective? If no, what do you think would help increase the effectiveness?

9. Does the trade union regularly review its sexual harassment policies?

10. Has the trade union worked together with organisations to devise and implement policies and procedures around sexual harassment and how cooperative were the organisations in working with the trade union?

11. What are the key challenges facing the trade union with regards to sexual harassment in the workplace?

12. Do you feel that the current sexual harassment legislation is clear and easily understandable?

13. Are there any current developments regarding sexual harassment which the trade union is working on? 


\section{Appendix D}

\section{Research consent form}

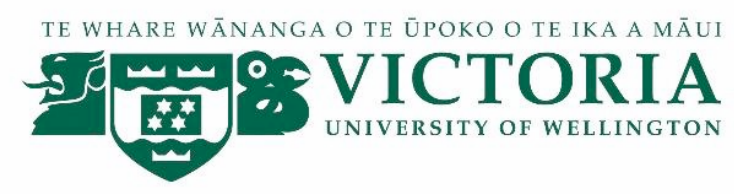

\section{A study of the interplay between law and organisational codes of conduct with regards to sexual harassment in the workplace in New Zealand.}

\section{INTERVIEWS: RESEARCH AGREEMENT}

I have read the Participant Information Sheet and understand the nature of the research. I have had the opportunity to ask any questions and have them answered to my satisfaction. I understand that I can ask further questions at any time.

I agree to take part in one audio-recorded semi-structured interview.

I understand that:

- My participation is completely voluntary. My name will not be used in reports, nor will any information that could easily identify me.

- I may withdraw from this study before data analysis begins [January 2017] without giving an explanation, and any information that I have provided will be returned to me or destroyed.

- The data will be securely kept for a period of up to five years after the completion of this project [January 2023] and then destroyed.

- No-one will have access to the recordings or any notes expect the researcher and supervisors.

- I understand that the results will be used for a Master's thesis, and a summary of the results may be used in academic publications, conference presentations, and public reports. 
- I will receive a transcript of the interview (if requested) and can give comments and feedback within 2 weeks of receipt.

- I will receive a summary of the final report for the project (if requested).

- I understand that I am free to decline to answer any question during the interview if I prefer not to provide an answer.

In the thesis and any future publications, I will be identified as:

Any other conditions for agreement:

I agree to take part in this research:

Name:

Organisation/Position:

Signature:

Date:

Contact details (for transcript and final report):

Researcher contact information Supervisor contact information 